\title{
Behaviour of combined channel/angle connections to tubular columns under monotonic and cyclic loading
}

\author{
C. Málaga-Chuquitaype and A. Y. Elghazouli \\ Department of Civil and Environmental Engineering, Imperial College London, UK
}

\begin{abstract}
This paper describes an experimental study into the behaviour of open beam-totubular column connections consisting of combined channel/angle components. Ten monotonic and cyclic tests on specimens with different angle sizes, channel dimensions and geometric arrangements, are described. The experimental set-up, connection configurations and material properties are first introduced followed by a detailed account of the results and observations from the tests. Based on the experimental results, the main behavioural patterns are discussed and the salient response characteristics such as stiffness, strength and energy dissipation are examined. Particular emphasis is given to the assessment of key detailing parameters such as the channel thickness, angle gauge distance and the presence of web angles. The cyclic tests also provide data on the susceptibility to low-cycle fatigue within critical connection components. These results enable an evaluation of the predictions of available fatigue damage models. Additionally, the experimental results offer direct information on the force-displacement response of the channel component for which simplified models are proposed. Finally, simple expressions for determining the overall stiffness and capacity of the overall joint are then discussed, and the parameters that have a most notable influence on their accuracy are highlighted. The experimental results presented in this paper also provide essential information for the future validation of more detailed numerical procedures.
\end{abstract}

Keywords: Angle/channel connections, tubular columns, semi-rigid joints, cyclic response. 


\section{Introduction}

Tubular steel columns offer several architectural and structural advantages over open members, particularly in terms of their strength-to-weight ratio, minor axis resistance, torsional stiffness and aesthetic appearance. Nevertheless, these merits may sometimes remain under-exploited due to the perceived difficulties and relative lack of design guidance on appropriate cost-effective connections between open beams and tubular columns. This dearth of information is even more pronounced with regards to the reliability of semi-rigid open beam-to-tubular column connections under cyclic loads.

Bolted connections with angles offer practical and economical merits, and their behaviour has been extensively studied for open beam-to-open column joints both experimentally and analytically [1-4]. It has been demonstrated [5-7] that, when properly designed, bolted semi-rigid connections can provide similar or even more favourable performance than their fully-rigid counterparts under various loading conditions.

On the other hand, to date, most of the attention on the performance of open beam to tubular column connections has focused on fully-rigid/fully-welded details [8-11] for which suitable design guidance is available [12]. Similarly, Eurocode 3 Part 1.8 [13] proposes rules for determining the resistance of fully welded tubular joints but lacks information on their semi-rigid/partialstrength counterparts. Nevertheless, the cost and inspection/maintenance implications associated with on-site welding, and their critical performance under cyclic loads remain as potential problems for this type of connection.

In contrast with fully-rigid connections, semi-rigid connections to tubular columns have received relatively less attention. Available studies include the study by White and Fang [14] in which tests were performed on five different connection configurations including fin plates, T-stubs, through plates and angles, welded to the face of tubular columns. Significant variation of stiffness was observed and the influence of column width was highlighted. Dawe and Grondin [15] conducted ten tests on seat angle connections shop-welded to the column face and site-bolted to the beam, based on which eight failure modes were identified. Maquoi et al. [16] evaluated the 
use of threaded studs welded to tubular columns and found the column face deformation to be the main contributor to the performance of the connection owing to the relatively thin sections employed. Neves [17] investigated the same connection configuration but with thicker column walls. It was found that the welding zone in the threaded studs was of critical importance and that the connection ductility was substantially reduced due to fracture of the stud.

Several investigations have also been carried out in order to explore the possibility of using thermal drilling techniques such as the flowdrill process in tubular connections both at the local $[18,19]$ and joint $[20,21]$ levels. France et al. [21] performed tests on full and partial depth end-plates flowdrilled to tubular columns and bolted to open beams. In general, the thermal drilling technique was reported to be adequate for column thickness between 5 and $12.5 \mathrm{~mm}$ whereas, for thicker plates, conventional drilling techniques were suggested. Nevertheless, practical issues seem to render the application of flowdrilling cumbersome and hamper its wider use.

Another alternative for bolted connections between open beams and tubular members is that offered by specially designed blind-bolts equipped with sleeves that expand inside the tube [19,22-27]. Korol et al. [26] performed tests on five end-plate bolted beam to column connection assemblies using Blind Oversized Mechanical Bolts (BOM) and High Strength blind-bolts $(H S B B)$ developed by Huck International Inc [27]. It was shown that the behaviour of open beam-to-tubular column connections using HSBB was similar to that using conventional bolts whereas a connection employing BOM bolts did not achieve equivalent levels of strength. Based on monotonic tests on three end-plate joints, France [28] compared the behaviour of Hollobolts [29] and flowdrill bolts, and suggested that flowdrill systems can provide relatively higher stiffness and capacity. Barnett et al. [30,31] carried out a review of different blind-bolting options and conducted an experimental study on blind-bolted T-stubs and connections using Hollo-bolts. More recently, Elghazouli et al. [32] performed seventeen tests on blind-bolted top and seat and top, seat and web angle connections between open beams and tubular columns under monotonic and cyclic loads. Three main inelastic mechanisms were identified, and both the Hollo-bolt grade and the gauge distance between the Hollo-bolt and beam flange were observed to have the most notable effect on the connection performance. Importantly, this study 
also showed that the extension induced within the Hollo-bolt and the deformations exhibited by the column face can constitute limiting factors in the application and design of this type of connection.

Owing to its versatility and ease of use the Reverse Channel Component is emerging as a detail with a potential for wider adoption in practice, offering a cost-effective and practical alternative for joining open beams to tubular columns. Reverse channel configurations incorporate a channel section which is shop-welded at the legs end to the face of the tubular column. The channel face is then connected on site to the open beam by means of any conventional bolted detail (e.g. end-plates, top, seat and/or web angles, T-stubs, etc.). Despite its potential, there is a dearth of experimental studies on connections incorporating reverse channel components, particularly under cyclic loading. Test results on the fire resistance of four end-plate reverse channel connections have been reported by Ding and Wang [33]. The behaviour was compared with other connection details between open beams and concrete filled tubular columns. It was concluded that reverse channel connections appear to have the best combination of structural performance and construction cost among the different configurations considered. However, there is a need for further assessment and characterization of the behaviour of various forms of reverse channel connections under both monotonic and cyclic loading conditions.

This paper examines the experimental response of reverse channel connections with bolted angles. It presents and discusses the results of monotonic and cyclic tests on ten top and seat as well as top, seat and web angle connections with different geometric configurations. A detailed description of the testing arrangement and material properties is given, and the main experimental results and salient behavioural observations are discussed. The discussion focuses on issues related to stiffness, capacity and failure mechanisms including fracture due to low-cycle fatigue. The implications of the findings on the performance and design of this type of connections are highlighted, and simplified models that provide an evaluation of the main design parameters are proposed. 


\section{Experimental set-up and details}

\subsection{Testing arrangement}

The arrangement used for testing the beam-to-column connections is shown schematically in Figure 1. In order to accommodate the large rotations expected in the connections, whilst maintaining the verticality of the actuator, a loading mechanism consisting of swivel hinges was constructed as indicated in Section A-A of Figure 1. A hydraulic actuator operating in displacement control was used to apply vertical deformation at the tip of the cantilever open beam. On the other hand, the tubular column was restrained at both ends with the aid of another reaction frame.

Vertical displacements and forces were recorded by the load cell and displacement transducer incorporated within the actuator at the tip of the beam. The verticality of the column was monitored through an inclinometer attached to it, while another inclinometer was placed on the beam to confirm the angle of rotation. Displacement transducers were used to measure the deformation at the face of the reverse channel component and at selected points along the beam length to monitor its deformation. Strain gauges were also used to measure strains at the beam flanges, at the expected locations of plastic hinges within the angles, and in the inner face of the reverse channel component at the midpoint between the top angle bolts.

\subsection{Connection specimens}

In total, ten open beam-to-tubular column semi-rigid reverse channel connections with angles were tested. Previous experimental work with reverse channel connections utilised conventional channel sections and bolted end-plates [33]. In the present study, the reverse channel components were obtained by longitudinal cutting of hot rolled tubular sections. This is believed to enhance the versatility and practicality of this type of connection due to the wider range available in tubular sections, hence offering a broader selection of width-to-thickness ratios than equivalent standard channel sections. After welding the legs of the reverse channel component to the face of the tubular columns, the open beam was connected to it by means of bolted angle cleats. 
A summary of the test series is given in Table 1, which includes the geometric details of the connection as well as the beam and column sizes. UB and SHS refer to Universal Beam and Square Hollow Sections, respectively. It should be noted that the channel was obtained by cutting the indicated SHS. Figure 2 illustrates the connection configurations utilised. The reference used for the specimens follows the format $D t-A x-d y-R$ where $D$ represents the specimen detail (for which $\mathrm{T}$ stands for top and seat angles and $\mathrm{W}$ for top, seat and web angle connections as indicated in Figure 2), $t$ is the thickness of the reverse channel in $\mathrm{mm}, x$ the thickness of the angle components in $\mathrm{mm}, y$ is the gauge distance measured between the centre of the bolt at the channel component and the beam flange in $\mathrm{mm}$, and $R$ reflects the testing regime (M for monotonic and Y for cyclic). SHS 200x200x10 members of 2 metre length were used in all cases as columns.

Grade 10.9 M16 standard bolts were employed in all specimens. Fillet welding with thickness of $10 \mathrm{~mm}$ was used throughout the length of the external face of the channel legs, and for a depth extending beyond the height of the top and seat angles. The average material yield strength and ultimate strength for the different components used (beams, columns, reverse channels and angle components) were obtained from at least three coupon tests and are presented in Table 2.

All beam-to-column connection tests were conducted under displacement-control conditions. In the monotonic tests, the displacement at the tip of the beam was increased gradually up to failure or until the stroke of the actuator was reached at $250 \mathrm{~mm}$. For the cyclic tests, the beam was lowered in order to accommodate deformations of up to $\pm 125 \mathrm{~mm}$ in both directions. The cyclic testing protocol shown in Figure 3 was used based on the recommendations provided by ECCS [34], where $\Delta$ is the applied displacement and $\Delta_{y}$ is the estimated yield displacement. After the maximum displacement was reached, all cyclic test specimens except Specimen T10A8-d40-Y were subjected to additional displacement reversals at an amplitude of $\pm 12 \Delta_{y}$ up to the point when fatigue fracture was observed in any of the connection components. For Specimen T10-A8-d40-Y, due to experimental constraints, additional displacement cycles at $\pm 10 \Delta_{y}$ amplitude were used instead until fracture occurred. 


\section{Main results and observations}

The main response parameters obtained form the tests are summarised in Tables 3 and 4, and the corresponding deformation patterns and moment-rotation relationships are presented in Figures 4 to 10. The initial stiffness and moment values at global connection yield were obtained from a bi-linear idealisation of the moment-rotation relationships. Due to the significant post-yield stiffness, values of moment at a joint rotation of $40 \mathrm{mrad}$ are also given in the tables. In addition to the measured initial stiffness and yield moment, Table 4 also includes the hysteretic energy dissipated per unit rotation for the cyclic tests. The hysteretic energy is defined as the summation of the areas enclosed by the moment-rotation curves. In subsequent sections, the experimental results and observations from the ten connection tests, described in Tables 1 to 4, are presented. Particular focus is given in the discussions to the influence of the following parameters on the connection behaviour: (1) gauge distance, (2) channel thickness and (4) presence of web angles.

\subsection{Monotonic tests}

\subsubsection{Deformation patterns}

The experimental program was designed with the aim of covering a reasonable range of practical configurations as well as to enable validation of the characterisation of individual connection components. This was accomplished by testing details representative of the boundaries in the connection deformation mechanism as well as other details representing intermediate behavioural patterns. To this end, the response of some specimens was expected to be largely determined by the influence of a specific connection component, such as the deformation in the angle component in Specimen T10-A8-d65-M (Figure 4a) or the deformation in the reverse channel in Specimen T6.3-A15-d40-M (Figure 4c). Other connection details (e.g. Specimen T10-A8-d40-M of Figure 4b) exhibited an intermediate deformation pattern with significant interaction between the constituent components. As expected, the interaction between the angle 
and reverse channel components had a direct influence on the inelastic behaviour of the connection. Angles with the longer leg connected to the channel (gauge distance of $65 \mathrm{~mm}$ ) typically yielded prior to the development of any significant deformation in the channel, whereas stiffer angles (i.e. gauge distance of $40 \mathrm{~mm}$ ) tended to concentrate considerable plastic deformation within the channel component. Importantly, regardless of the yield mechanism observed, all connections exhibited high ductility capacities well beyond the common rotation requirements in design codes, without showing significant degradation in stiffness or capacity. The momentrotation curves of the five monotonic tests are given in Figure 5. The deformation patterns shown in Figure 4 are discussed in more detail in subsequent sections with respect to the influence of key geometric parameters on the overall connection behaviour.

\subsubsection{Gauge distance}

The influence of gauge distance can be assessed by comparing the results of Specimens T10A8-d65-M and T-10-A8-d40-M in which the gauge distance was varied from $65 \mathrm{~mm}$ in the former to $40 \mathrm{~mm}$ in the latter while retaining all other geometric and material characteristics. Figures $6 \mathrm{a}$ and $6 \mathrm{~b}$ depict the observed yield deformation patterns of the above mentioned tests. As expected, Specimen T10-A8-d65-M, which has the longer leg attached to the $10 \mathrm{~mm}$ thick channel, developed two clear plastic hinges in the vertical leg with negligible deformation observed in the face of the channel component. On the other hand, in Specimen T10-A8-d40-M more significant plastic deformations were induced in the reverse channel component. This can be further confirmed by observing the strain measurements depicted in Figures 6c and 6d. From these figures it can be observed that the strains in the reverse channel in Specimen T10-A8-d65-M remain below yield up to rotation demands of over $100 \mathrm{mrad}$. On the other hand, yielding was observed in the reverse channel of Specimen T10-A8-d40-M at a rotation of around $40 \mathrm{mrad}$. The location of the plastic hinges near the bolts in the vertical leg was also clearly different, with plasticity occurring below the bolt head in Specimen T10-A8-d65-M. On the other hand, the plastic mechanism that formed in Specimen T10-A8-d40-M was displaced towards the bolt centerline and more significant bolt rotations were evident. 
The observed plastic deformation patterns have a direct influence on the resulting moment rotation relationships as illustrated in Figure 6e. Although the difference in the initial stiffness is insignificant, the connection capacity is greatly reduced by increasing the gauge distance. Increasing the gauge distance from $40 \mathrm{~mm}$ to $65 \mathrm{~mm}$ causes a $40 \%$ reduction in the overall connection capacity. As shown in Figure 6e, three clear behavioural stages are identifiable on the moment-rotation curve of Specimen T10-A8-d65-M, corresponding to an initial elastic phase maintained up to a rotation of around $5 \mathrm{mrad}$, a second plastic stage and a third stiffening phase starting at 60 mrad caused by second order tension effects. In contrast, this large displacement tension stiffening stage is not clearly evident in the moment-rotation of Specimen T-10-A8-d40-M which is attributed to the greater rotations observed in the bolts in this case.

\subsubsection{Reverse channel thickness}

The influence of the reverse channel thickness is illustrated in Figure 7. The figure provides a comparison of the response of Specimens T10-A8-d40-M and T6.3-A8-d40-M with channel thickness of $10 \mathrm{~mm}$ and $6.3 \mathrm{~mm}$, respectively. As expected, the thickness of the reverse channel affects the flexibility and capacity of this component which in turn have a direct influence on the joint response. Figures $7 \mathrm{a}$ and $7 \mathrm{~b}$ illustrate such influence on the deformation pattern at large rotation demands. As can be observed from these figures, the more flexible the channel component is, the less is the deformation required from the angle for comparable joint rotations. The influence on the deformation is more evident by comparing Figures $7 \mathrm{c}$ and $7 \mathrm{~d}$. When a relatively thick channel is employed (Specimen T10-A8-d40-M), yield strains are reached in the toe of the vertical leg of the angle earlier (at rotations of near $20 \mathrm{mrad}$ ). On the other hand, when a relatively thin angle is used (Specimen T6.3-A8-d40-M), yield strains are reached at a later stage (60 mrad rotation) at the same location on the toe of the vertical angle leg. This is due to the concentration of plastic deformations at an early stage in the face of the channel component, leading to a reduction in the deformation demands imposed on the angle component.

The influence of the reverse channel thickness on the connection stiffness and capacity is de- 
picted in the moment-rotation curves presented in Figure 7e as well as in the results summarised in Table 3. A reduction in the channel face thickness from $10 \mathrm{~mm}$ to $6.3 \mathrm{~mm}$ results in nearly $50 \%$ drop in stiffness and about $30 \%$ decrease in the connection capacity.

\subsubsection{Web angles}

Recent research carried out on blind-bolted angle connections to tubular columns [32] has shown the inclusion of web angles to be effective in increasing the connection stiffness and capacity provided that the local plasticity of the column face is prevented. To this end, Specimen W10A8-d40-M employs a UB305x165x40 beam of width larger than the effective reverse channel width. The effective width of the reverse channel face refers to the flat part of the SHS (i.e without the curved corners). This proved effective in minimising the channel face deformations on the compression zone of the connection, thus improving the overall joint performance. Figure 8 shows views of the deformed shape of Specimen W10-A8-d40-M.

The enhancement in the connection stiffness and capacity due to the addition of web angles can be examined by comparing the results of Specimens W10-A8-d40-M and T10-A8-d40-M where the main difference is the addition of web angles in the former. However, variability in the material properties of the angles used in the two specimens (as indicated in Table 2) and some dimensional differences (like the distance $h$ in Table 1 and Figure 2) require the momentrotation curves to be normalised prior to the comparison. This normalisation (Figure 9) was performed with respect to the initial attainment of yield in the vertical leg of the top angle with due consideration of the different material and geometric properties. It can be concluded from Figure 9 and the non-normalised values presented in Table 3, that the inclusion of web angles enhances the initial stiffness, capacity and post-elastic hardening properties of the joint. 


\subsection{Cyclic behaviour}

\subsubsection{Hysteretic response}

The cyclic moment-rotation curves obtained for the reverse channel connections under study are presented in Figure 10. It is clear from these plots that all specimens exhibited largely stable hysteretic behaviour with gradual transition between elastic and inelastic response. Furthermore, the moments developed were consistent with those observed in the corresponding monotonic tests as evident by comparing Tables 3 and 4. As shown in Figure 10, the reloading branch changes with increasing rotation levels but always reaches the same point at which the previous cycle unloaded. On the other hand, the unloading branches are largely parallel to each other regardless of the level of rotation.

Due to the accumulation of plastic deformations in the angle and channel components, residual deformations develop. This leads to flattening of the hysteresis loops during the load reversal, owing to the reduction in the angle resistance. However, an increase of stiffness occurs when contact with the column is resumed in the compression region. The slippage in the standard bolts connected to the beam also contributes to this phenomenon. As expected, this pinching behaviour is more evident when higher capacities are reached such as in the case of Specimens T10-A8-d40-Y and W10-A8-d40-Y in Figures 10a and 10e, respectively. In all cases, rotations exceeding $\pm 50 \mathrm{mrad}$ were reached without signs of notable stiffness or strength deterioration.

The cyclic behaviour of Specimen T6.3-A15-d40-Y which is depicted in Figure 10d deserves special attention. As noted before, Specimen T6.3-A15-d40-Y was designed in order to isolate the behaviour of the reverse channel component by forcing most of the deformation to occur within the channel face (i.e. a very stiff angles with $15 \mathrm{~mm}$ thickness were used). Therefore, as shown in Figure 10d, although considerable moments were mobilised, the pinching effect was, in relative terms, not as severe as in other cases. This is attributed to the domination of the channel rather than the angle components in this test. 


\subsubsection{Ductility and energy dissipation}

The reverse channel connections examined in this study exhibited high ductility under monotonic and cyclic loading conditions. One of the additional objectives of the present study was to investigate the low-cycle fatigue behaviour of the connections. Accordingly, high amplitude cycles were imposed on all specimens until fracture occurred in any of the components. However, as discussed in more detail below, it should be noted that this only took place at rotation levels which are well beyond those expected under characteristic seismic loading conditions.

Figure 11 presents an assessment of the energy dissipation in the cyclic tests. The curves depict the cumulative dissipated energy versus cumulative rotation, whilst the rate of energy dissipated per unit rotation is also given in Table 4. As expected, there is a direct relationship between the stiffness/capacity of the connection and the energy dissipation capabilities. Accordingly, the connections incorporating web angles exhibited comparatively high levels of energy dissipation. Also, the reverse channel component (which is particularly dominant in Specimen T6.3-A15$\mathrm{d} 40-\mathrm{Y}$ as discussed before) is shown to be a good source of energy dissipation.

\subsubsection{Fatigue Damage}

As noted previously, additional cycles were applied up to failure at an amplitude of $\pm 12 \Delta_{y}$ for Specimens T6.3-A8-d65-Y, T10-A8-d65-Y, T6.3-A15-d40-Y and W10-A8-d40-Y while additional cycles at $\pm 10 \Delta_{y}$ were applied for Specimen T10-A8-d40-Y. In all tests, except T6.3A15-d40-Y fracture was observed at the base of the vertical leg of the top or seat angle, an example of which is presented in Figure 12a for Specimen T6.3-A8-d40-Y. On the other hand, owing to the largely elastic behaviour of the top and seat angles, Specimen T6.3-A15-d40-Y experienced fracture in the corners of the reverse channel component as illustrated in Figure 12c.

Depending on the angle gauge distance and the level of deformation accumulated in the channel components, the fatigue life was different for each specimen. For example, crack initiation was observed in Specimen T10-A8-d40-Y at the first peak of the twenty first cycle (fifth cycle at $\left.+10 \Delta_{y}\right)$ and full fracture at the next $-10 \Delta_{y}$ peak. As expected, Specimen T6.3-A8-d40-Y 
accumulated more deformation within the reverse channel face than Specimen T10-A8-d40-Y and hence the angle fracture was delayed until the first peak of the thirtieth cycle (at an amplitude of $\left.+12 \Delta_{y}\right)$. Furthermore, the higher deformation demands experience by the reverse channel face on Specimen T10-A8-d40-Y led to damage around the bolt holes in the channel component (as shown in Figure 12b). This damage was reflected in the slight (but sustained) stiffness degradation observed in the hysteretic response in Figure 10b starting from the twenty third cycle onwards. Specimen T10-A8-d65-Y also experienced fatigue fracture in the toe of the angle component which initiated at the last peak of the twenty second cycle and was fully developed at the first peak of the twenty third cycle (both at amplitudes of $\pm 12 \Delta_{y}$ ). Finally, Specimen W10-A8-d40-Y was also subjected to cyclic loads until fatigue fracture was observed in the bottom angle. This occurred at the first $+12 \Delta_{y}$ inelastic excursion during the twentieth cycle.

The data obtained from the test results provide useful information for the validation of detailed damage models $[35,36]$. In such models, fatigue life is usually expressed as a function of the plastic strain in the fracture zone - a value that is not always easy or practical to measure accurately. Alternatively, fatigue damage models based on the connection rotation have been proposed [37,38]. Mander et al. [37] developed fatigue life relationships for top and seat angle connections based on the effective joint plastic rotation. Later on, the model was extended to deal with cycles of variable amplitude [38]. These models were validated for rotation levels below 40 mrad.

To assess the suitability of the models discussed above, Figures 13, 14 and 15 present the fatigue life analysis for Specimens T10-A8-d40-Y, T6.3-A8-d40-Y and T10-A8-d65-Y, respectively. In these figures, the effective rotation $\theta_{j p}$ is defined as the net joint plastic rotation induced by plastic deformation in the angles only (i.e. discounting elastic rotations as well as rotations induced by the deformations in the reverse channel component). Figures 13b, 14b and 15b depict the strain histories obtained from strain gauge measurement closest to the zone of fracture. Two fatigue damage models are compared in Figures 13c, 14c and 15c. Miner's model considers linear damage accumulation obtained by summation of the damage caused by individual cycles, 
such that:

$$
D_{T}=\sum D_{i}=\sum \frac{1}{N_{f}}
$$

where $D_{T}$ is the total accumulated damage, $D_{i}$ is the damage fraction corresponding to cycle $i$, and $N_{f}$ is the number of cycles to failure defined by Mander et al. [38] as:

$$
\theta_{j p}=0.0849\left(2 N_{f}\right)^{-0.333}
$$

The second fatigue damage model presented in Figures 13c, 14c and 15c corresponds to an energy based approach [38] for which the damage $D(t)$ at time $t$ is expressed as:

$$
D(t)=\sum\left[\left(\frac{M_{i}+M_{i-1}}{2}\right)\left(\theta_{j i}-\theta_{j i-1}\right) \frac{\theta_{j p i}}{0.0229 M_{j p}}\right]
$$

where $i$ is the data point in the cyclic history, $\theta_{j p i}$ is the effective plastic equiamplitude rotation defined as the effective plastic rotation minus the rotation obtained from the cyclic momentrotation envelope, whilst $M_{i}$ and $\theta_{i}$ are the observed moment and rotation, respectively, at instant $i$.

It can be observed from Figures 13c, 14c and 15c that the energy-based model gives more favourable results than the linear Miner's rule damage accumulation for all cases in comparison with the experimental results. This seems to suggest the validity of the range of applicability of the selected models for rotation amplitudes higher than the $40 \mathrm{mrad}$ for which the models were originally proposed. 


\section{Design considerations}

This section discusses the key parameters and criteria that can be of direct relevance to practical design application. It also offers a simplified preliminary assessment of possible models for the evaluation of the connection stiffness and capacity. Due to the availability of information in the literature on the behaviour and modelling of angle components [e.g. 1-4], emphasis is given here to the characterization of the channel component, followed by and assessment of the overall connection response.

\subsection{Reverse channel component}

The behaviour of the reverse channel component can be assessed by considering the response of Specimens T6.3-A15-d40-M and T6.3-A15-d40-Y presented in Figures 5 and 10d, respectively. By providing very stiff angles as well as beams of width comparable to that of the reverse channel, these tests ensured that the plastic deformation occurred mainly in the tension side of the reverse channel as illustrated in Figure 16a. The plastic deformation observed at large rotations and can be idealised through the plastic mechanism indicated in Figure 16b. $L$ is defined as the reverse channel width, $c$ and $i$ as the bolt pitch dimensions depicted in Figure 2a, $R_{m}$ as the radius of the circular portion of the yield line mechanism, $t_{c}$ as the reverse channel thickness, $\sigma_{y}$ as the material yield strength, and $d_{h}$ and $d_{b h}$ as the bolt hole and bolt head diameter, respectively. On this basis, the plastic capacity of the reverse channel in tension $F_{c f}$ can be derived as:

$$
F_{c f}=\frac{\sigma_{y} t_{c}^{2}}{2}\left(\frac{2 R_{m}-d_{h}}{2 R_{m}-d_{b h}}\right)\left[\pi \frac{d_{h}-R_{m}}{d_{h}-2 R_{m}}+2 \frac{i+c-d_{h}}{2 R_{m}-d_{h}}\right]
$$

where $R_{m}$ represents:

$$
R_{m}=\frac{L-i-t_{c}}{2}
$$


Additionally, the stiffness of the column face can be determined through the following relationship proposed by Elghazouli et al. [32]:

$$
K_{c}=\frac{\pi E_{s} t_{c}^{3}}{12\left(1-\nu^{2}\right) C \frac{L^{2}}{4}}
$$

where $E_{s}$ is the Young's modulus of steel, $\nu$ is Poisson's ratio for steel, and $C$ is a coefficient which is assumed as 0.18 [32] based on calibration studies using detailed continuum finite element models.

Finally, assuming a post elastic stiffness of $15 \%$ of the initial stiffness as suggested for components of similar out-of-plane plate behaviour [17], a bi-linear characterization of the forcedisplacement relationship of the reverse channel component can be constructed. Such bi-linear relationship is presented in Figure 16c and compared with the experimental data. This comparison demonstrates that the above described modelling assumptions appear reasonable. Therefore, such expressions are employed in the estimation of the overall joint rotational stiffness and plastic capacity in the following section.

\subsection{Connection initial stiffness and capacity}

In order to examine the stiffness characteristics of reverse channel connections with angles, the simplified component-based model of top and seat angle connections suggested in Eurocode 3 Part 1.8 [13] is considered herein as presented in Figure 17a. This model was further extended to consider top, seat and web angle connections by Pucinotti [39] as presented in Figure 17b. For simplicity, a pre-defined point of rotation can be assumed at the horizontal leg of the bottom angle for top and seat angle connections. Hence, the initial rotational stiffness of the connection is given by:

$$
S_{T}=k_{T} y_{T}^{2}=\sum 1 / K_{j}{ }^{-1} y_{T}^{2}
$$


where $K_{j}$ is the stiffness of the $j^{\text {th }}$ component and $y_{T}$ is the distance between the top angle bolt row and the horizontal leg of the bottom angle.

On the other hand, when web angles are included, the higher capacities reached and the additional rotational restraint imposed by the web cleats can alter the point of rotation. This effect would be aggravated if the compression contact region is substantially smaller than the reverse channel width, hence inducing significant deformations [32]. A mechanical model that considers the reverse channel compression stiffness $k_{\text {comp }}$ and replaces the web and top angle rows by an equivalent spring with stiffness $k_{e q}$ can be constructed (Figure 17b). In this case, for connections with top, set and web angle components, the following expression can be derived for $S_{T}[39]$ :

$$
S_{T}=\frac{y_{e q}}{1 / k_{c o m p}+1 / k_{e q}}
$$

in which $k_{e q}$ and $y_{e q}$ are given by:

$$
\begin{aligned}
k_{e q} & =\frac{\sum k_{i} y_{i}}{y_{e q}} \\
y_{e q} & =\frac{\sum k_{i} y_{i}^{2}}{\sum k_{i} y_{i}}
\end{aligned}
$$

where $k_{i}$ is the stiffness of the $i^{\text {th }}$ bolt row, and $y_{i}$ defines the location of the bolt-row with reference to the assumed point of rotation.

With regards to capacity, a first approach, often leading to conservative estimates of capacity, would be to ignore the plasticity in the horizontal leg of the angle assemblage. This leads to the 
following set of expressions, which are analogous to the equivalent T-stub concept suggested in Eurocode 3 [13]:

$$
M_{y 1}=\min \left(M_{A, R d}, M_{b A, R d}, M_{b, R d}\right)
$$

in which the yield capacity of the connection $M_{y 1}$ is determined as the smallest value obtained from Equations 12, 13 or 14 corresponding to the different plastic patterns as follows:

a) Mode 1: formation of plastic mechanism in the angle:

$$
M_{A, R d}=\frac{2 m_{p l}}{d^{\prime}} y
$$

b) Mode 2: mixed failure mode involving yielding of the bolt and a plastic hinge in the angle:

$$
M_{H b A, R d}=\frac{2 m_{p l}+\sum B_{y} c^{\prime}}{c^{\prime}+d^{\prime}} H
$$

c) Mode 3: Bolt yielding:

$$
M_{H b, R d}=\sum B_{y} H
$$

where $B_{y}$ is the smaller of the yield force in the bolt, or in the reverse channel component as defined by Equation 4; $m_{p l}$ is the plastic moment capacity of the longitudinal angle section, and $c^{\prime}$ and $d^{\prime}$ are the effective gauge distances defined as:

$$
\begin{gathered}
c^{\prime}=c+\left(1-f_{\text {pry }}\right) \frac{d_{b}}{2} \\
d^{\prime}=c+d-\left(c^{\prime}+t_{f}+0.8 r\right)
\end{gathered}
$$

in which $c$ and $d$ are the nominal gauge distances shown in Figure $2, t_{f}$ is the angle thickness, $r$ is the angle root radius, and $f_{\text {pry }}$ is a factor that takes into account the change in the location of plastic hinges. Such change in plastic hinge location is, as described previously, related to the 
ratio between the stiffness of the bolt and the stiffness of the angle component, with plasticity occurring near to the bolt centerline for stiffer angles and below the bolt head for more flexible ones. In this respect, assuming that $k_{B}$ represents the bolt axial stiffness, the factor $f_{\text {pry }}$ can be taken as 1 when $k_{B}<3\left(d-t_{f}-0.8 r\right)^{3} / E I$ and 0 for $k_{B}>12\left(d-t_{f}-0.8 r\right)^{3} / E I[40]$. A linear interpolation between these suggested limits provides representative results.

Figure 18 presents comparisons between the experimental monotonic moment-rotation curves and the bi-linear estimations obtained by means of the expressions described in this section, whereas Figure 19 compares such bi-linear predictions with the corresponding envelope of the moment-rotation relationships obtained from the cyclic tests. A post-yield hardening stiffness of $5 \%$ was used in accordance with the experimental data.

It is clear from Figures 18 and 19, that the suggested simplified procedure provides adequate estimations of the stiffness and capacity in all cases, provided appropriate gauge lengths are employed (Equations 15 and 16). The comparisons are particularly encouraging for specimens T6.3-A8-d40-M and T10-A8-d65-M and for the envelope of specimens T6.3-A8-d40-Y and T10A8-d65-Y. Nevertheless, the inclusion of web angles in specimens W10-A8-d40-M and W10-A8$\mathrm{d} 40-\mathrm{Y}$ induce complex interactions between the connection components, hence requiring more detailed models to trace the full response more accurately; nonetheless, the initial stiffness is well predicted and the proposed simplified expressions offer a reasonable lower bound estimate of the moment capacity in the connections. This underestimation in the joint moment capacity is attributed to the fact that at the attainment of yielding in the top angle component (i.e. the point at which the capacity is calculated in the simplified model) there is still significant reserve in capacity that is supplied by the web angle components at later stages.

\subsection{Practical application}

The experimental results and observations presented in this paper provide essential data for the validation of future detailed analytical models for reverse channel connections with angles. In general, the tests demonstrate the satisfactory inelastic performance of this type of reverse 
channel connections under monotonic and cyclic loading conditions. In the previous section, the stiffness and capacity properties of connections were highlighted as two key aspects required in assessment and design procedures. These can be determined through detailed non-linear models, or by using simplified approaches such as those examined in the two previous sections. Additionally, the available ductility observed in the specimens was well in excess of the rotational demands commonly expected under severe monotonic or cyclic loads. Clearly, the experimental data should firstly be complemented by extensive parametric studies using more detailed numerical models.

It is important to note that the connection configurations considered herein represent average levels of stiffness and relatively modest capacity ranges. When conventional classification conventions [13] are used, the specimens considered in this study would lie in the lower half of the semi-rigid/partial-strength category. Clearly, besides the specific connection details, such classification would strongly depend on the attached beam. If the approach adopted in Eurocode $3[13]$ is used, the connection stiffness would be normalised to that of the beam expressed as $E I_{b} / L_{b}$, where $I_{b}$ is the second moment of area of the beam and $L_{b}$ is the length of the beam, respectively. In turn, the connection capacity would be normalised with respect to the plastic capacity of the beam. In this case, the boundary between the semi-rigid/partial-strength and the flexible/pinned classifications is suggested in Eurocode 3 [13] as 0.5 in terms of normalised stiffness, and 0.25 in terms of normalised capacity. Considering possible practical ranges of $I_{b}$ and $L_{b}$ and the results obtained in this study, the normalised stiffness falls between approximately 1 and 2.5 for top and seat angles only, and increases to above 4 when web angles are included. In terms of normalised yield capacity, the range would be between 0.15 and 0.3 for top and seat angle connections and can reach 0.6 when web angles are incorporated.

In terms of fatigue life, the experimental results described herein show that reverse channel connections are able to withstand inelastic cyclic deformations beyond those experienced by steel structures under severe seismic excitations, without suffering significant stiffness or strength deterioration. This characteristic, together with the considerable post-yield hardening exhibited by this form of connection make such forms particularly suitable for secondary lateral resisting 
systems where the connections are required to achieve adequate ductility while at the same time maintaining the gravity loading carrying capacity of the frames.

\section{Concluding Remarks}

This paper examined the behaviour of reverse channel connections with angles for open beamto-tubular column joints. The experimental programme enabled a direct assessment of the influence of a number of key considerations, such as the angle gauge distance, the reverse channel thickness, and the presence of web angles on the overall connection behaviour. The test results also provide essential information for the future validation of detailed analytical models.

As expected, it was observed that the inelastic mechanisms exhibited by this type of connection stem from the relative contribution of the constituent components. It was shown that the angle gauge distance is inversely proportional to the connection capacity with a less significant effect on the stiffness. On the other hand, the flexibility of the reverse channel component, examined herein by varying the channel thickness, has a direct influence on both the initial stiffness and capacity of the connection. Besides, it was shown that the addition of web angles can significantly enhance the overall resistance in the elastic and post-elastic ranges. The tests also highlighted the importance of ensuring the presence of an adequate mechanism for transferring the compression forces to the column in order to achieve satisfactory performance.

In terms of ductility, the reverse channel connections investigated in this paper reached rotational levels exceeding $120 \mathrm{mrad}$ under monotonic loading and well over $50 \mathrm{mrad}$ under cyclic loading. These rotational capacities are well beyond the demands expected under typical design scenarios. Relatively stable hysteretic response was observed under cyclic loading in all cases with reasonably good energy dissipation capabilities, although more notable pinching behaviour was observed with the increase in the capacity of the connection. The low-cycle fatigue life was also studied by subjecting the specimens to cycles of high rotation levels up to fracture. Fracture occurred in the top and seat angle components in all the specimens with the exception of Specimen T6.3-A15-d40-Y in which the channel component dominated the behaviour. The 
applicability of fatigue damage models based on effective plastic rotation of the connection was demonstrated, with the energy based model proposed by Mander et al. [38] showing favourable comparison with he test results.

After the characterisation of the reverse channel force-deformation relationship, simplified mechanical models for estimating the initial stiffness and moment capacity of the connection were assessed. In general, simplified procedures adapted from the equivalent T-stub approach employed in Eurocode 3, in conjunction with the use of appropriate gauge distances, provide reliable estimates of the connection stiffness and capacity. Overall, the experimental findings, coupled with the simplified analytical treatments, highlight the suitability of this form of semirigid/partial-strength connection for secondary or braced primary frame systems.

\section{Acknowledgements}

The financial support of Corus Tubes for the research described in this paper is gratefully acknowledged. The authors would also like to thank the technical staff of the Structures Laboratories at Imperial College London, particularly Mr. T. Stickland and Mr R. Millward, for their assistance with the experimental work. Finally, the first author would like to acknowledge the UK EPSRC for the award granted to conduct his doctoral research.

\section{References}

[1] Garlock M, Ricles J, Sause R. Cyclic load tests and analysis of bolted top and seat angle connection. Journal of Structural Engineering, American Society of Civil Engineering 2003; 129(12):1615-1625.

[2] Kukreti A, Abolmaali A. Moment-rotation hysteresis behavior of top and seat angle steel frame connections. Journal of Structural Engineering, American Society of Civil Engineering 1999; 8:810-820.

[3] Shen J, Astaneh-Asl A. Hysteretic behavior of bolted angle connections. Journal of Constructional Steel Research 1999; 51:201-218.

[4] Shen J, Astaneh-Asl A. Hysteretic model of bolted angle connections. Journal of Constructional Steel Research 2000; 54:317-343.

[5] Elnashai A, Elghazouli A, Denesh-Ashtiani F. Response of semirigid steel frames to cyclic and earthquake loads. Journal of Structural Engineering, American Society of Civil Engineering 1998; 124(8):857-867. 
[6] Leon RT, Hoffman JJ, Staeger PE. Partially restrained composite connections - a design guide, steel deisgn guide series, American Institute of Steel Construction, Chicago, 1996.

[7] Elghazouli A. Ductility of frames with semirigid connections. 11th World Conference on Earthquake Engineering, Acapulco, Mexico, 1996.

[8] Cao J, Packer J, Kosteski N. Design guidelines for longitudinal plate to HSS connections. Journal of Structural Engineering, American Society of Civil Engineering 1998; 124(7):784-791.

[9] Kosteski N, Packer J. Longitudinal plate and through plate-to-hollow structural section welded connections. Journal of Structural Engineering, American Society of Civil Engineering 2003; 129(4):478-486.

[10] Kosteski N, Packer J. Welded tee to HSS connections. Journal of Structural Engineering, American Society of Civil Engineering 2003; 129(2):151-159.

[11] Kurobane Y. Connections in tubular structures. Progress in Structural Engineering and Materials $2002 ; 4(1): 35-45$.

[12] Kurobane Y, Packer J, Wardenier J, Yeomans N. Design guide for structural hollow section column connections. Serie CIDECT Construction with Hollow Sections. TUV-Verlag, Germany, 2004 .

[13] CEN. EN 1993-1-8, Eurocode 3: Design provisions of steel structures, part 1.8: Design of joints 2005.

[14] White R, Fang P. Framing connections for square structural tubing. Journal of the Structural Division, American Society of Civil Engineering 1966; 92(ST2):175-194.

[15] Dawe J, Grondin G. W-shape to RHS column connections. Canadian Journal of Civil Engineering 1990; 23:788-797.

[16] Maquoi R, Naveau X, Rondal J. Column welded stud connections. Journal of Constructional Steel Research 1984; 4:3-26.

[17] Neves LF. Comportamento monotnico e cclico de ligacoes de eixo fraco e tubulares em estruturas metalicas e mistas aco-betao. [in portuguese]. PhD Thesis, University of Coimbra, Portugal 2004.

[18] Banks G. Flowdrilling for tubular structures. Proceedings of the Fifth International Conference on Tubular Structures, Nottingham, 1993.

[19] Ballerini M, Piazza M, Bozzo E, Occhi F. Shear capacity of blind bolted connections for RHS steel structural elements. Proceedings of the Seventh International Conference on Tubular Structures, Kansas, 1996; 99-106.

[20] France J, Davison B, Kirby P. Strength and rotational response of moment connections to tubular columns using flowdrill connectors. Journal of Constructional Steel Research 1999; 50:1-14.

[21] France J, Davison B, Kirby P. Strength and rotational stiffness of simple connections to tubular columns using flowdrill connectors. Journal of Constructional Steel Research 1999; 50:15-34.

[22] Occhi F. Hollow section connections using (hollowfast) hollowbolt expansion bolting, second interim report 6G-16/95. Technical Report, Sidercad, Italy 1995.

[23] Klippel S. Recent design developments with blind mechanically operated bolt systems for use with hollow section steelwork. Journal of Constructional Steel Research 1998; 46:267-268.

[24] Dutta D, Wardenier J, Yeomans N, Sakae K, Bucak O, Packer J. Fabrication, assemblage et montage des structures en profils creux. Serie CIDECT Guide de dimensionnement \%. TUVVerlag, Germany, 1999. 
[25] Banks G. Hollowbolt joint shear tests project no S2860. Technical Report, British Steel Plc., Swinden Technology Centre, Rotherham 1997.

[26] Korol R, Ghobarah A, Mourand S. Blind bolting W-shape beams to HSS columns. Journal of Structural Engineering, American Society of Civil Engineering 1999; 119(12):3463-3481.

[27] Huck International Inc. Industrial fastening systems, Arizona, USA 1990.

[28] France J. Bolted connections between open section beams and box columns. PhD Thesis, Department of Civil and Structural Engineering, University of Sheffield, UK 1997.

[29] Lindapter International Ltd. Type HB hollo-bolt for blind connection to structural steel and structural tubes, Bradford, England 1995.

[30] Barnett T, Tizani W, Nethercot D. The practice of blind bolting connections to structural hollow sections: A review. Steel and Composite Structures 2001; 1:1-16.

[31] Barnett T, Tizani W, Nethercot D. Blind bolted moment resisting connections to structural hollow sections. Connections in Steel Structures IV, Virginia, 2000.

[32] Elghazouli A, Málaga-Chuquitaype C, Castro J, Orton A. Experimental monotonic and cyclic behaviour of blind-bolted angle connections. Engineering Structures 2009; 31(11):2540-2553.

[33] Ding J, Wang Y. Experimental study of structural fire behavior of steel beam to concrete filled tubular column assemblies with different types of joints. Engineering Structures 2007; 29:34853502 .

[34] ECCS, European Convention for Constructional Steelwork. Recommended testing procedure for assessing the behaviour of structural steel elements under cyclic loads, Brussels 1986.

[35] Azizinamini A, Radziminski JB. Static and cyclic performance of semirigid steel beam-to-column connections. Journal of Structural Engineering, American Society of Civil Engineering 1989; 115(12):2979-2999.

[36] Ballio G, Calado L, Castiglioni CA. Low cycle fatigue behaviour of structural steel members and connections. Fatigue and Fracture of Engineering Materials and Structures 2007; 20(8):11291146 .

[37] Mander J, Stuart S, Pekcan G. Low-cycle fatigue behavior of semirigid top and seat angle connections. Engineering Journal AISC 1994; third quarter(3):111-122.

[38] Mander J, Stuart S, Pekcan G. Low-cycle variable amplitude fatigue modeling of top-and-seat angle connections. Engineering Journal AISC 1995; second quarter(3):54-62.

[39] Pucinotti R. Top-and-seat and web angle connections: prediction via mechanical model. Journal of Constructional Steel Research 2001; 57:661-694.

[40] Málaga-Chuquitaype C. Seismic behaviour and design of steel frames incorporating tubular members. PhD Thesis, Department of Civil and Environmental Engineering, Imperial College London, London, UK 2010 (In preparation). 


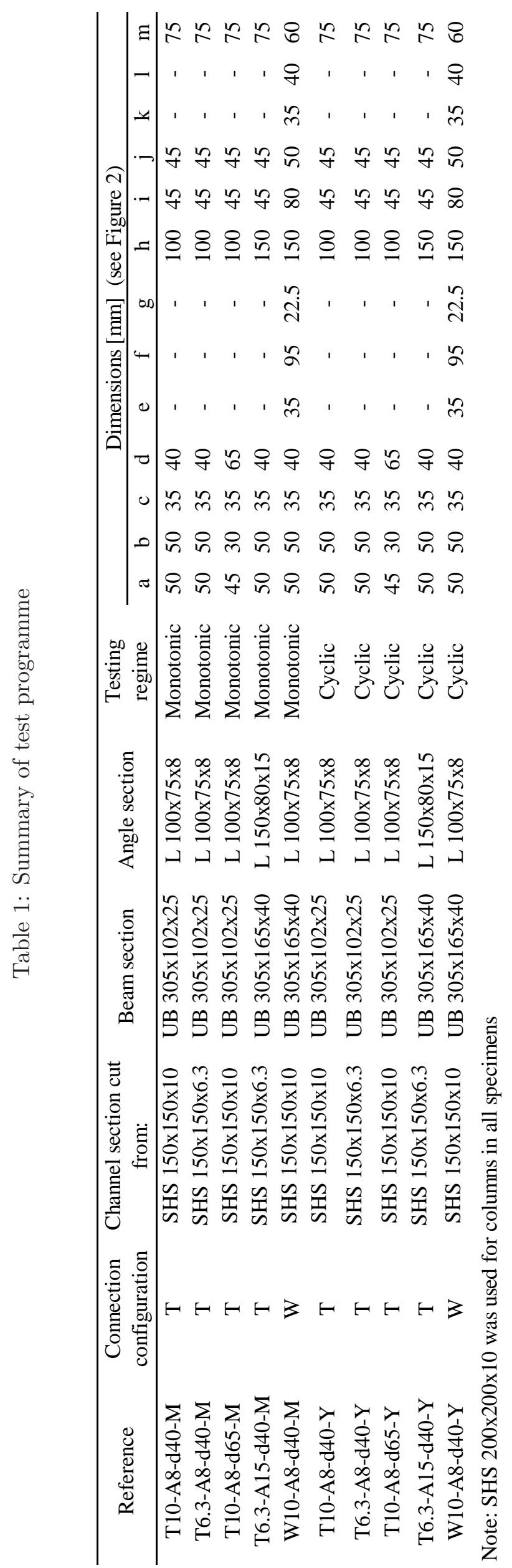


Table 2: Material properties

\begin{tabular}{|c|c|c|}
\hline Component & $\begin{array}{c}\text { Average yield } \\
\text { strength }\left[\mathrm{N} / \mathrm{mm}^{2}\right]\end{array}$ & $\begin{array}{l}\text { Average ultimate } \\
\text { strength }\left[\mathrm{N} / \mathrm{mm}^{2}\right] \\
\end{array}$ \\
\hline SHS 200x200x10 & 511 & 556 \\
\hline SHS $150 \times 150 \times 10$ & 400 & 502 \\
\hline SHS $150 \times 150 \times 6.3$ & 385 & 485 \\
\hline UB305x102x25 & 329 & 443 \\
\hline L 150x80x15 & 293 & 449 \\
\hline L 100x75x8 (A) ${ }^{1}$ & 312 & 438 \\
\hline L $100 \times 75 \times 8(B)^{2}$ & 252 & 381 \\
\hline \multicolumn{3}{|c|}{$\begin{array}{r}{ }^{1} \text { Used in Specimens T10-A8-d40-M, T6.3-A8-d40-M, T10-A8-d65-M, } \\
\text { T10-A8-d40-Y, T6.3-A8-d40-Y and T10-A8-d65-Y }\end{array}$} \\
\hline
\end{tabular}

Table 3: Summary of results for monotonic tests

\begin{tabular}{cccc}
\hline Reference & $\begin{array}{c}\text { Initial stiffness } \\
{[\mathrm{kNm} / \mathrm{rad}]}\end{array}$ & $\begin{array}{c}\text { Moment at yield } \\
{[\mathrm{kNm}]}\end{array}$ & $\begin{array}{c}\text { Moment }[\mathrm{kNm}] \text { at } \\
\text { 40 mrad rotation }\end{array}$ \\
\hline T10-A8-d40-M & 3982 & 22.7 & 34.0 \\
T6.3-A8-d40-M & 1880 & 16.0 & 22.2 \\
T10-A8-d65-M & 2410 & 12.1 & 17.3 \\
T6.3-A15-d40-M & 3459 & 21.1 & 38.5 \\
W10-A8-d40-M & 4928 & 34.0 & 57.5
\end{tabular}

Table 4: Summary of results for cyclic tests

\begin{tabular}{ccccc}
\hline Reference & $\begin{array}{c}\text { Initial stiffness } \\
{[\mathrm{kNm} / \mathrm{rad}]}\end{array}$ & $\begin{array}{c}\text { Moment at yield } \\
{[\mathrm{kNm}]}\end{array}$ & $\begin{array}{c}\text { Moment }[\mathrm{kNm}] \text { at } \\
40 \mathrm{mrad} \text { rotation }\end{array}$ & $\begin{array}{c}\text { Rate of energy } \\
\text { dissipation }[\mathrm{kJ} / \mathrm{rad}]\end{array}$ \\
\hline T10-A8-d40-Y & 3623 & 22.1 & 32.7 & 12.8 \\
T6.3-A8-d40-Y & 1938 & 15.5 & 22.8 & 10.2 \\
T10-A8-d65-Y & 2406 & 13.0 & 16.0 & 8.1 \\
T6.3-A15-d40-Y & 3806 & 23.6 & 40.3 & 17.2 \\
W10-A8-d40-Y & 5108 & 34.0 & 60.0 & 20.7
\end{tabular}



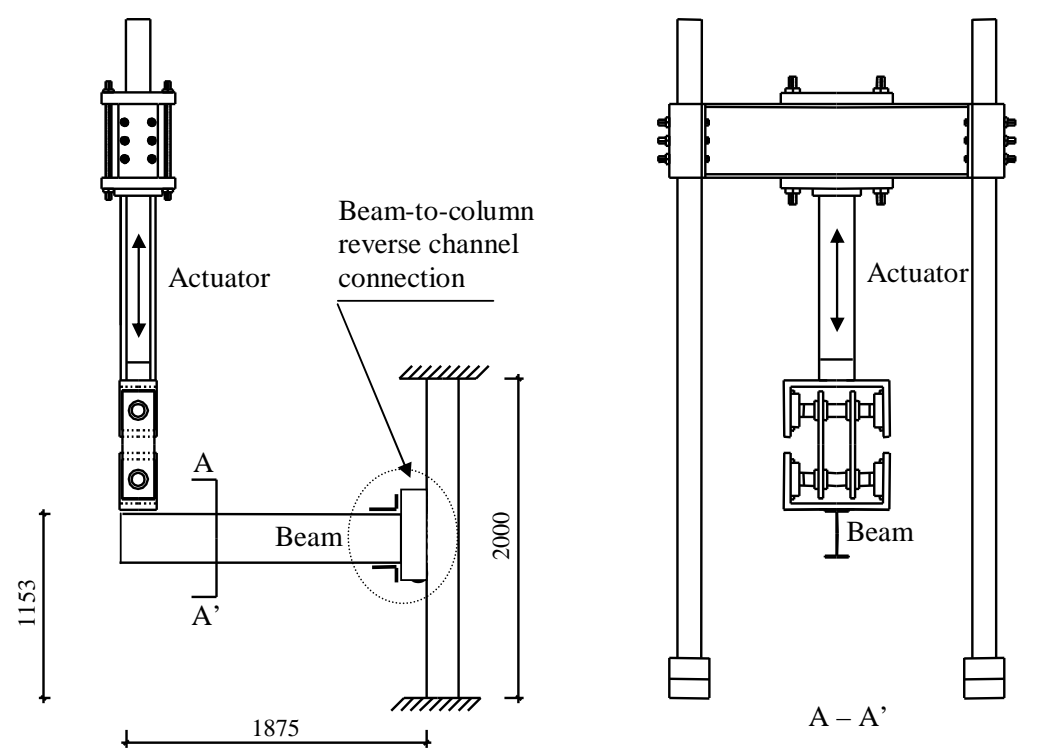

Figure 1: Experimental set-up 


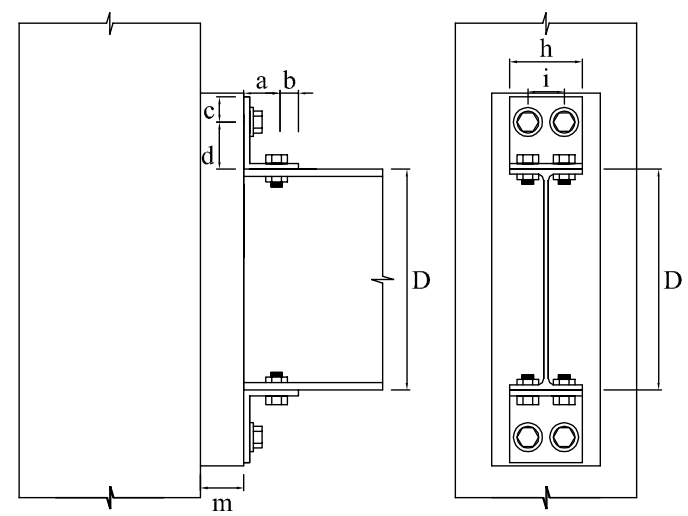

(a) Connection Type $\mathrm{T}$

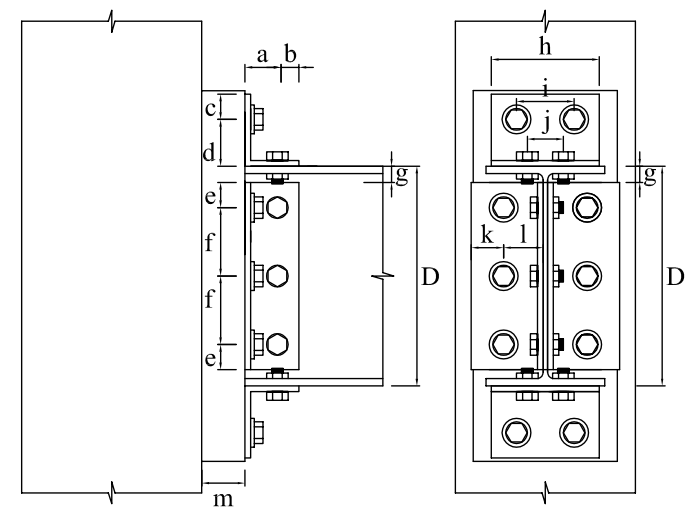

(b) Connection Type W

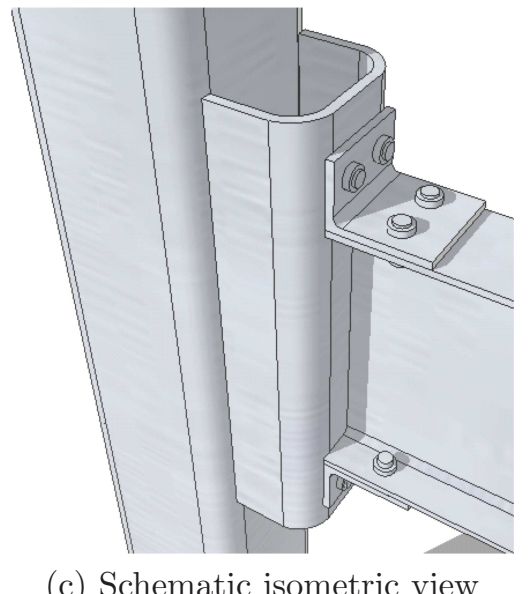

(c) Schematic isometric view

Figure 2: Details of connection configurations 


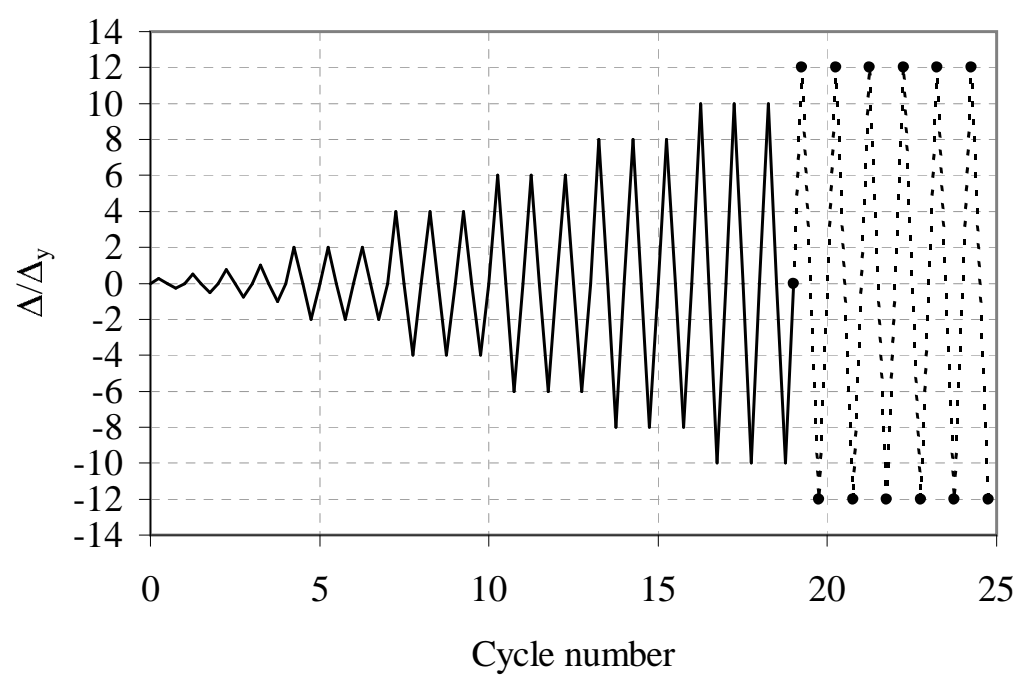

Figure 3: Loading protocol adopted in the cyclic tests [34]

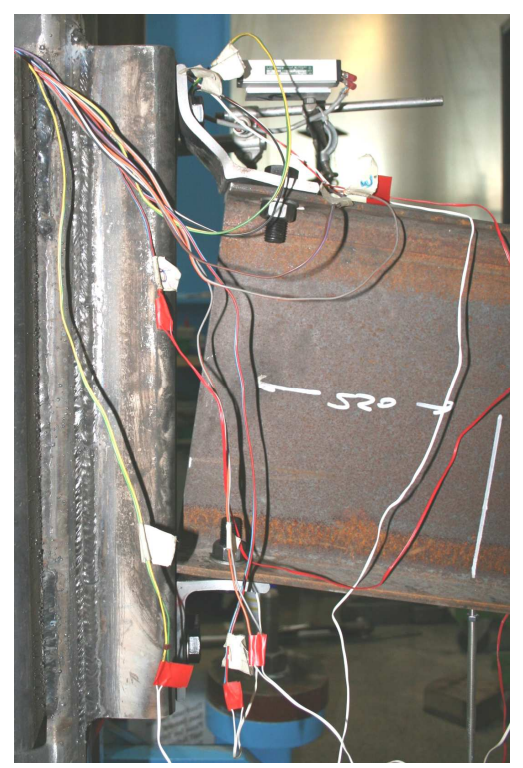

(a) Deformation at the end of test in Specimen T10-A8-d65-M

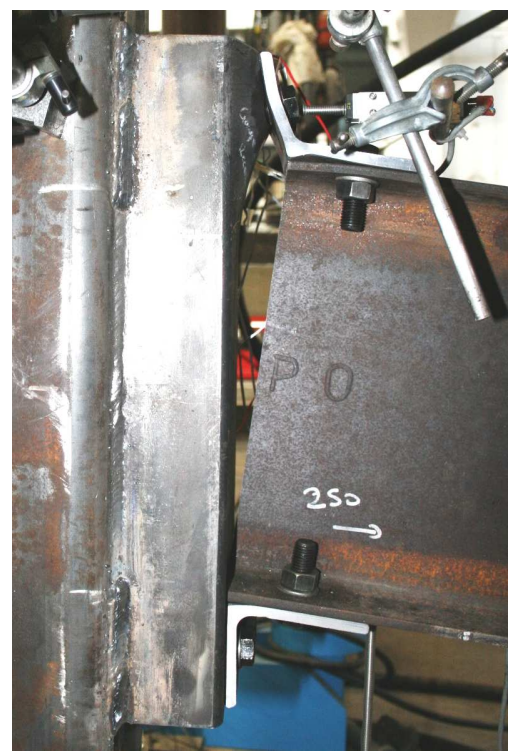

(b) Deformation at the end of test in Specimen T6.3-A8-d40-M

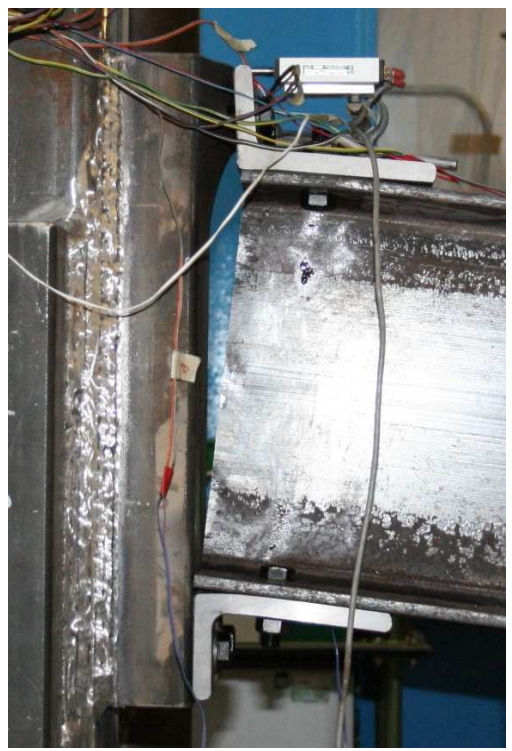

(c) Deformation at the end of test in Specimen T6.3-A15-d40-M

Figure 4: Main deformation patterns observed in monotonic tests 


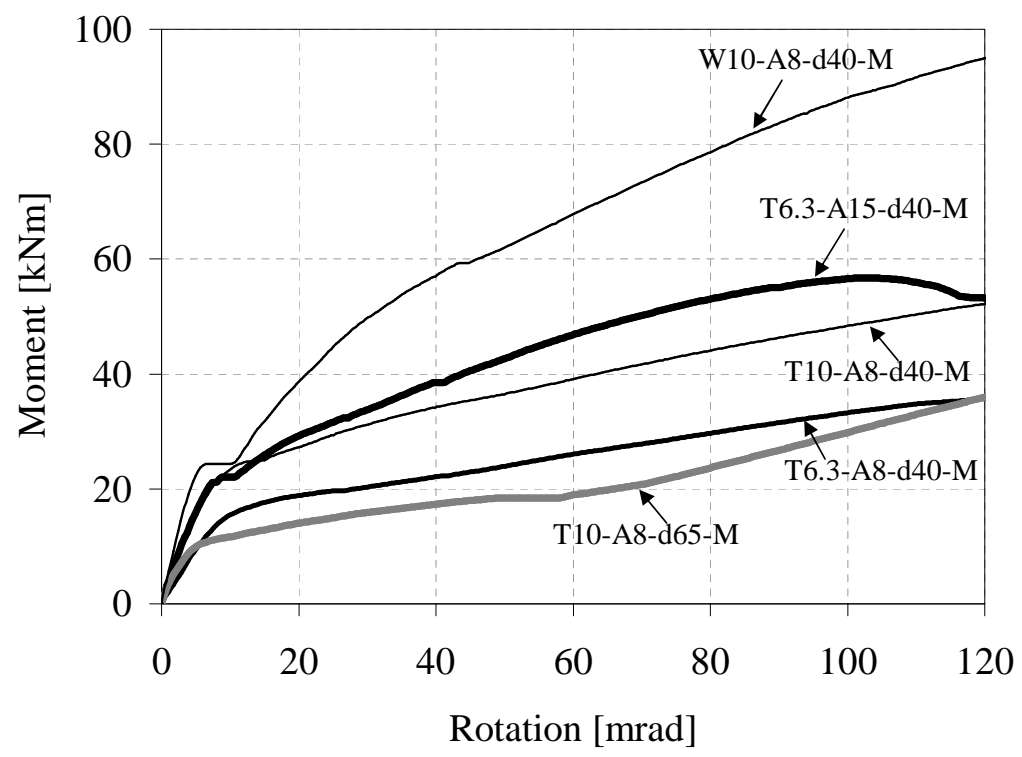

Figure 5: Moment-rotation relationships for monotonic tests 


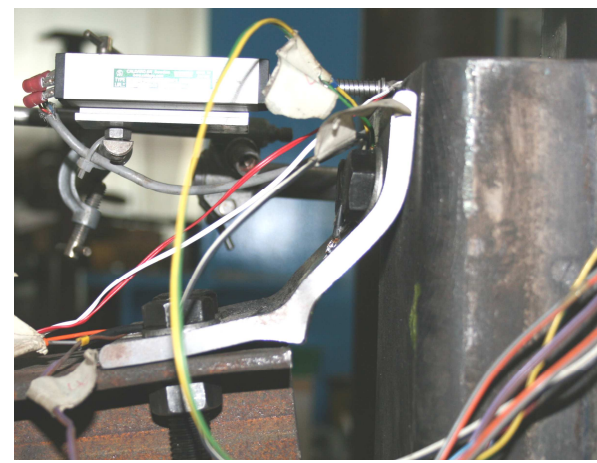

(a) Deformation mode at the end of the test in Specimen T10-A8-d65-M

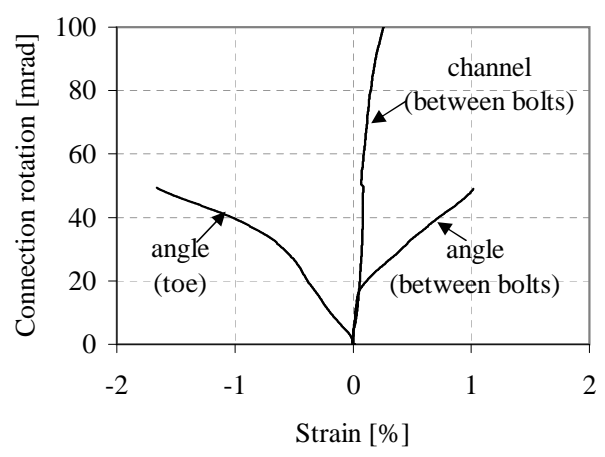

(c) Measured strains in the vertical leg of the top angle of Specimen T10-A8d65-M

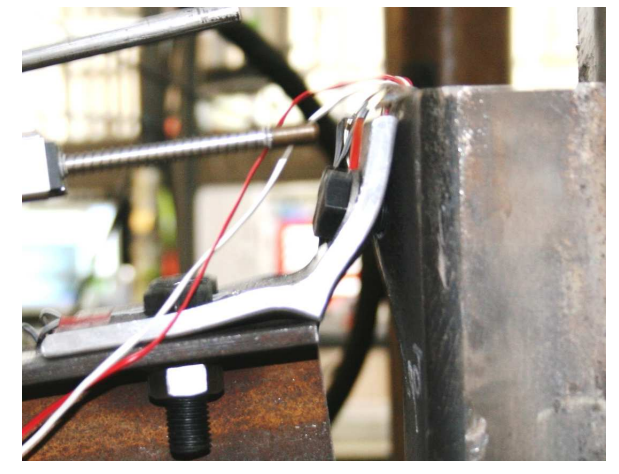

(b) Deformation mode at the end of the test in Specimen T10-A8-d40-M

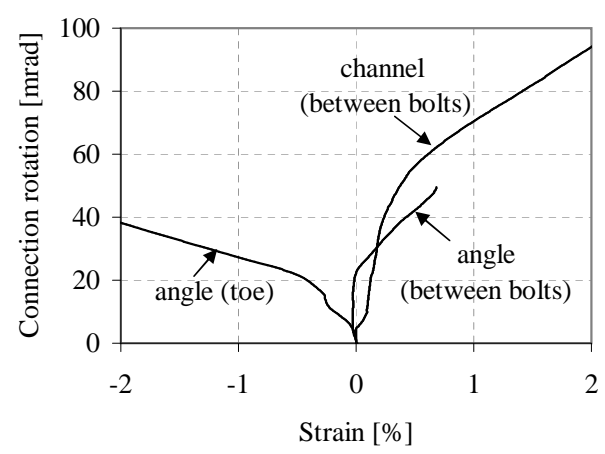

(d) Measured strains in the vertical leg of the top angle of Specimen T10-A8d40-M

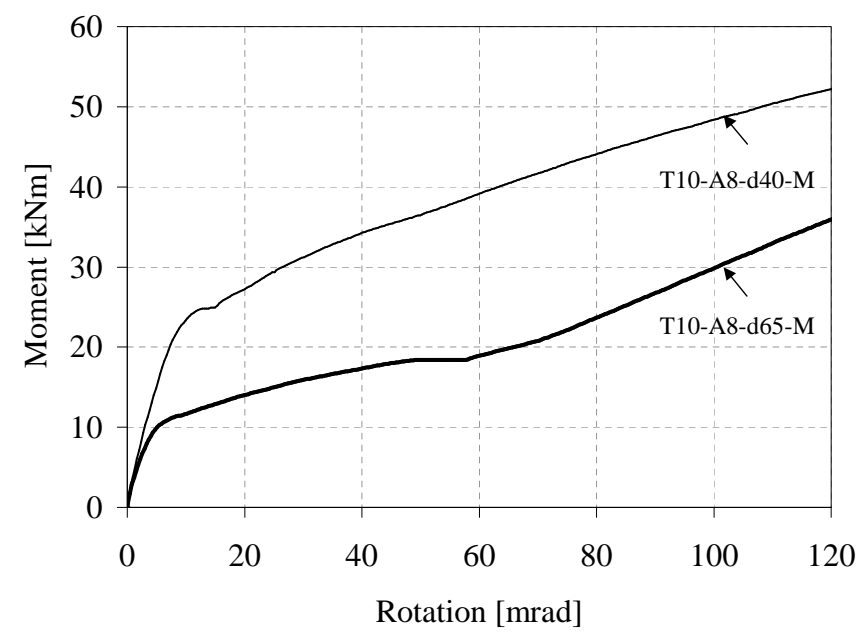

(e) Moment-rotation relationships for Specimens T10A8-d65-M and T10-A8-d40-M

Figure 6: Influence of gauge distance 


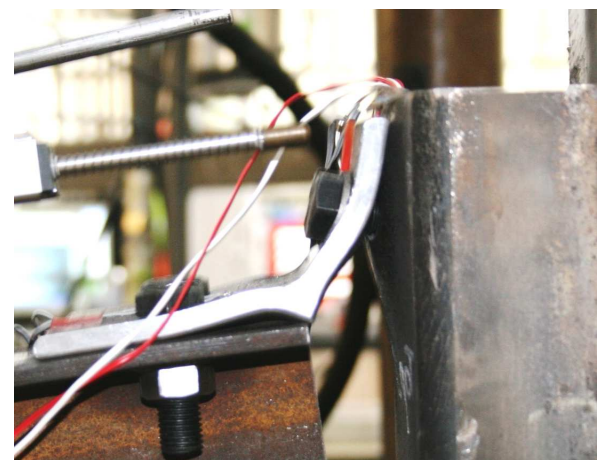

(a) Deformation mode at the end of the test in Specimen T10-A8-d40-M

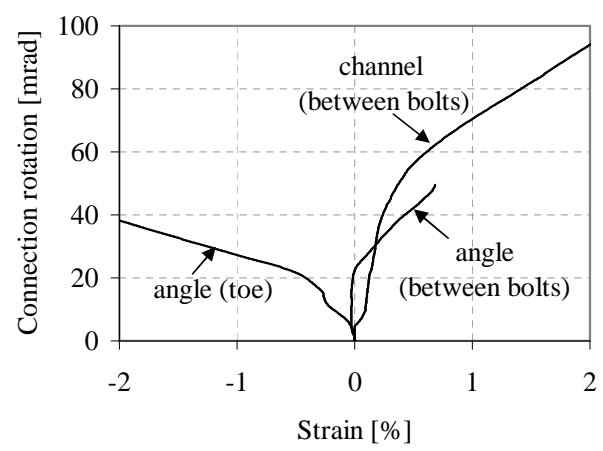

(c) Measured strains in the vertical leg of the top angle of Specimen T10-A8d40-M

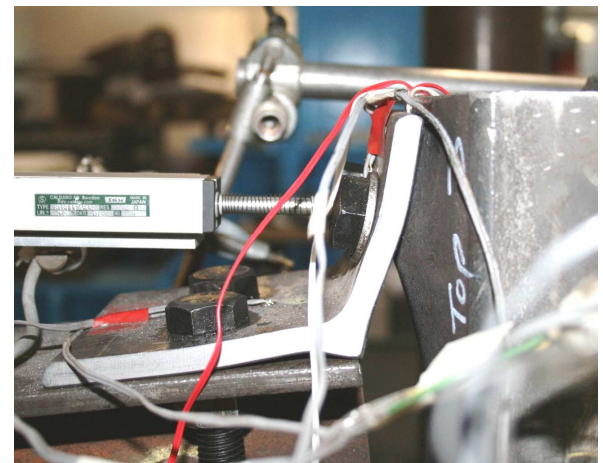

(b) Deformation mode at the end of the test in Specimen T6.3-A8-d40-M

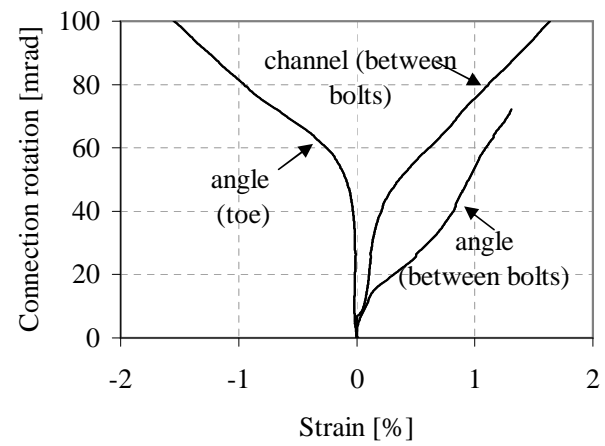

(d) Measured strains in the vertical leg of the top angle of Specimen T6.3-A8d40-M

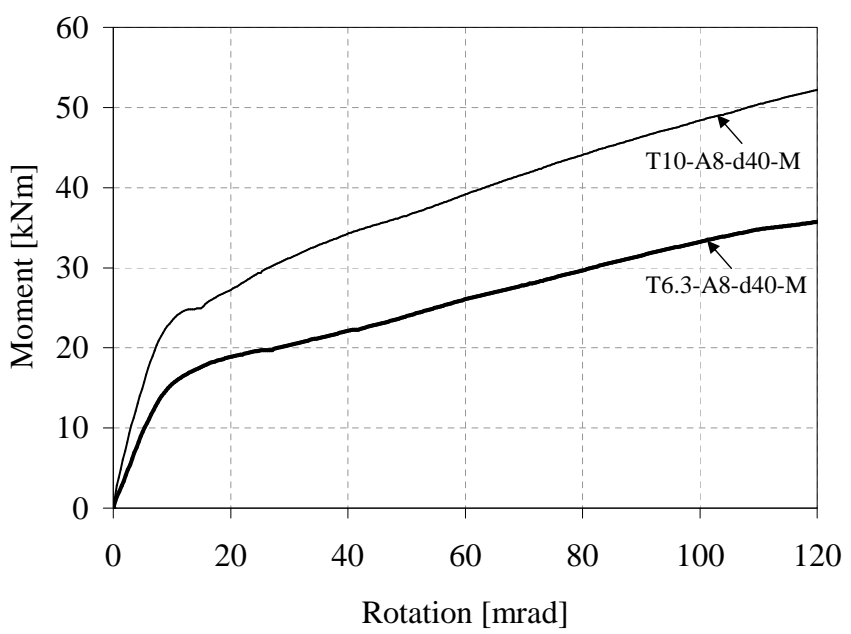

(e) Moment-rotation relationships for Specimens T10A8-d40-M and T6.3-A8-d40-M

Figure 7: Influence of channel thickness 


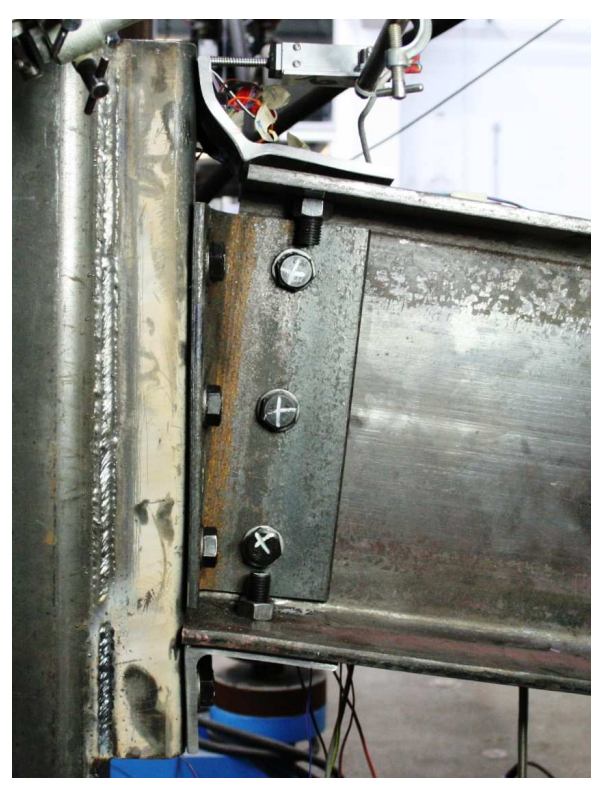

(a) General view

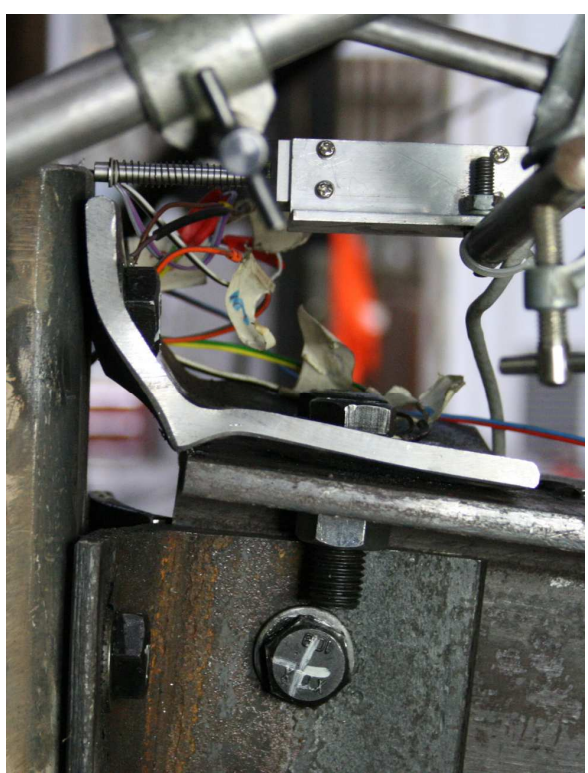

(b) Close view of the top angle component

Figure 8: Deformation at the end of test in Specimen W10-A8-d40-M

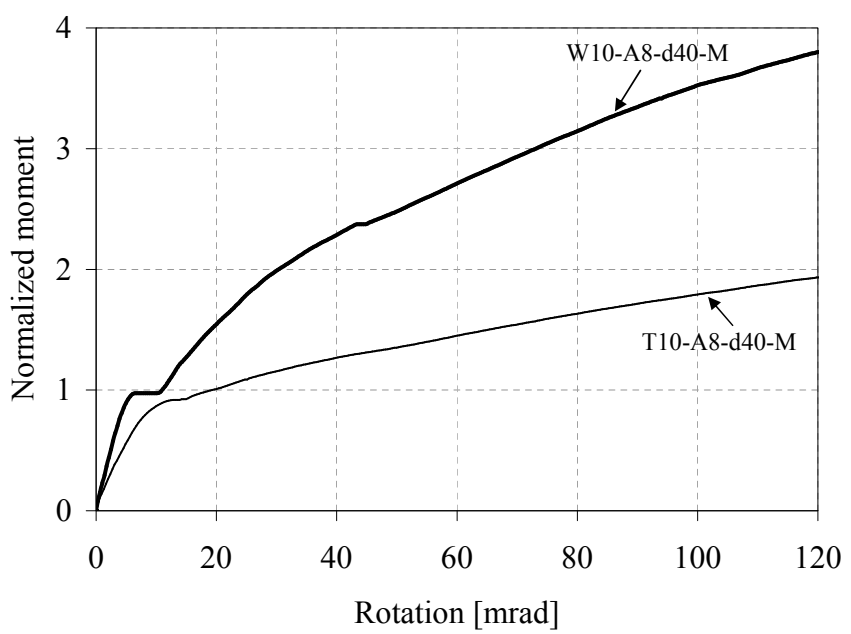

Figure 9: Influence of web angles 


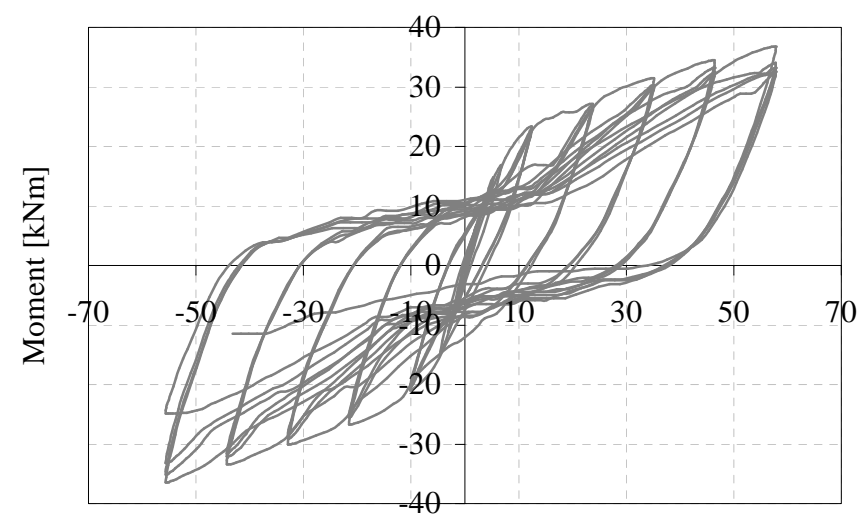

Rotation [mrad]

(a) Specimen T10-A8-d40-Y

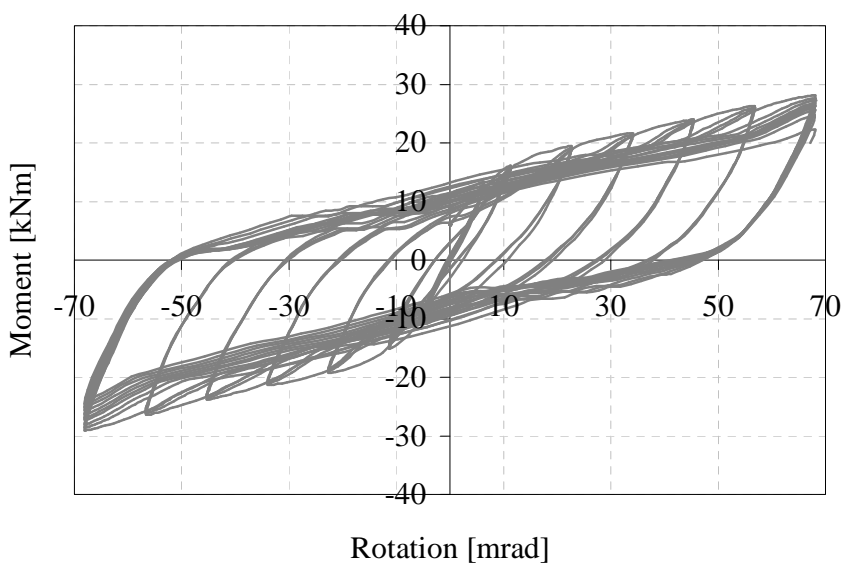

(b) Specimen T6.3-A8-d40-Y

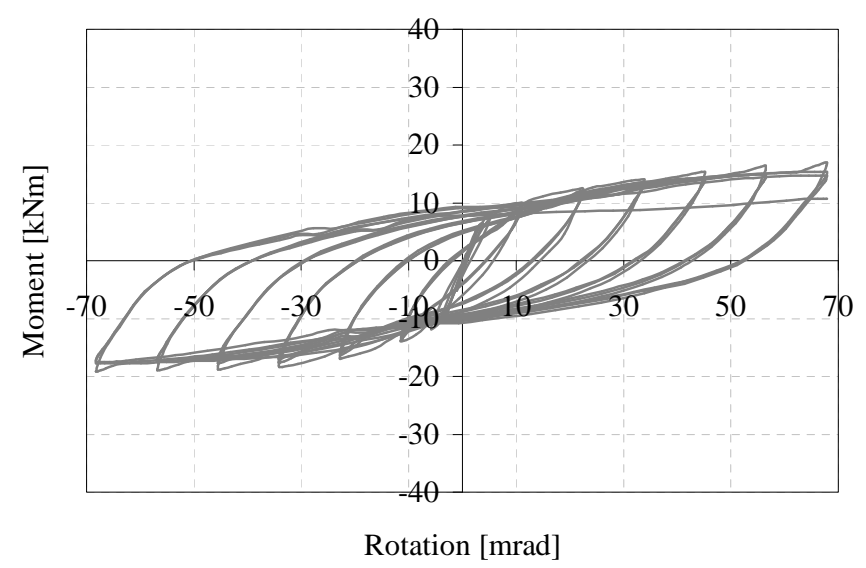

(c) Specimen T10-A8-d65-Y

Figure 10: Hysteretic moment-rotation relationships 


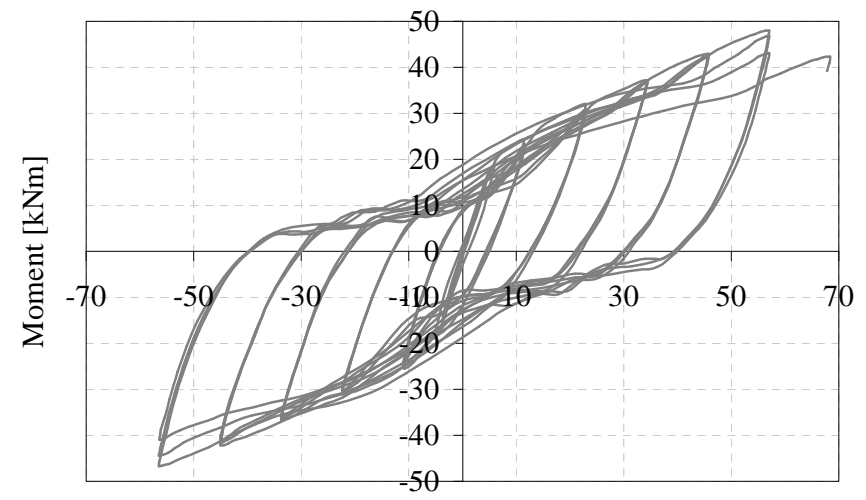

Rotation [mrad]

(d) Specimen T6.3-A15-d40-Y

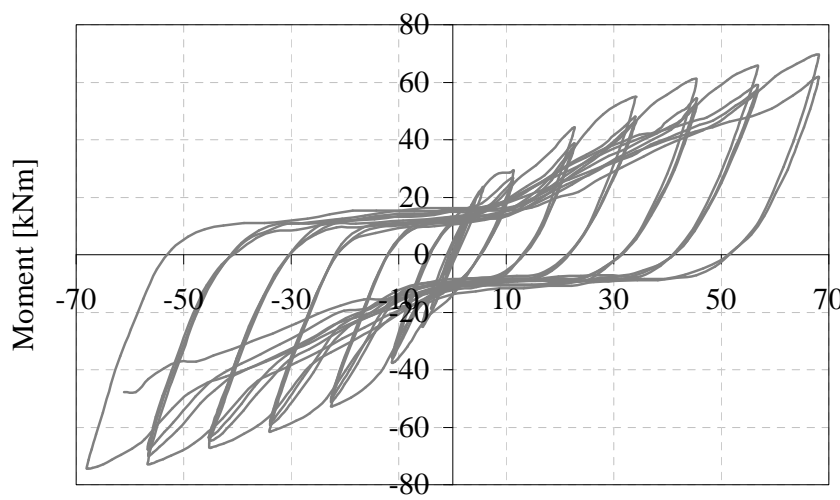

Rotation [mrad]

(e) Specimen W10-A8-d40-Y

Figure 10: Hysteretic moment-rotation relationships (Cont.) 


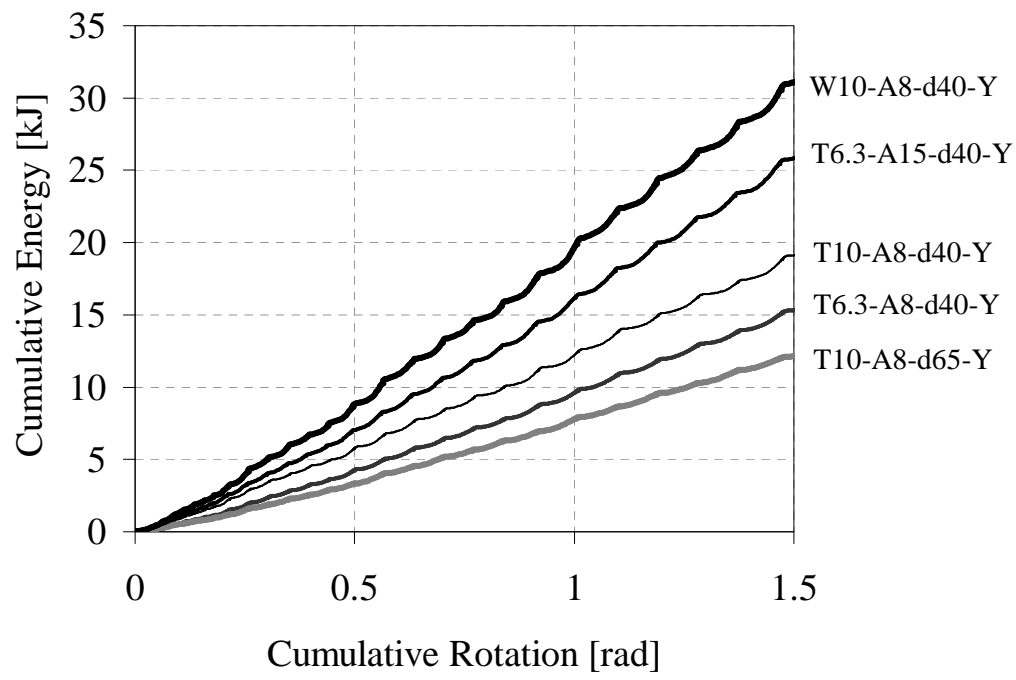

Figure 11: Cumulative energy dissipation

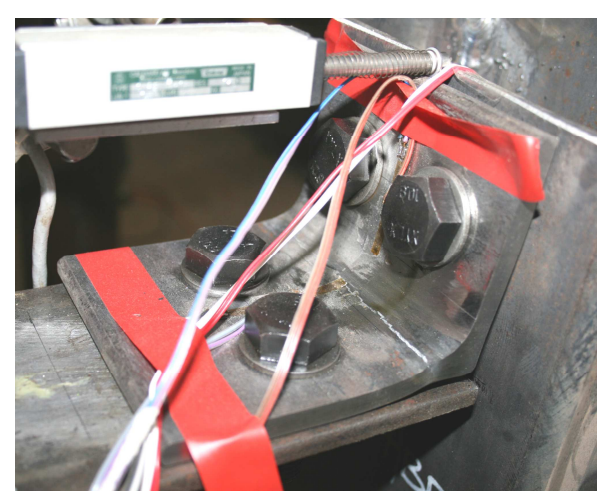

(a) Typical low-cycle fatigue fracture in top angle(Specimen T6.3-A8-d40-Y)

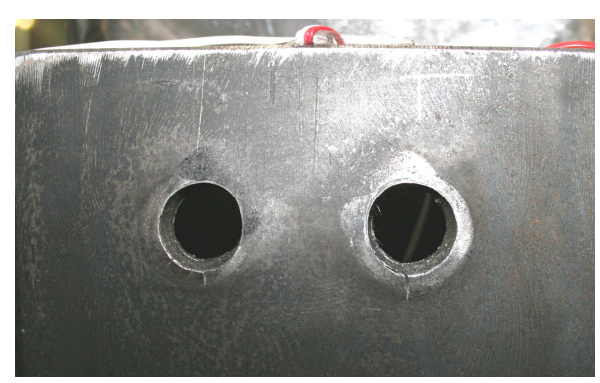

(b) Fatigue damage around bolt holes in reverse channel component (Specimen T6.3-A8-d40-Y)
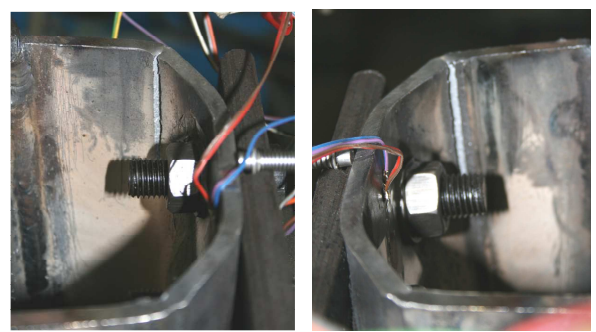

(c) Low cycle fatigue fracture in the corners of the reverse channel component of Specimen T6.3-A15-d40-Y

Figure 12: Fatigue damage 


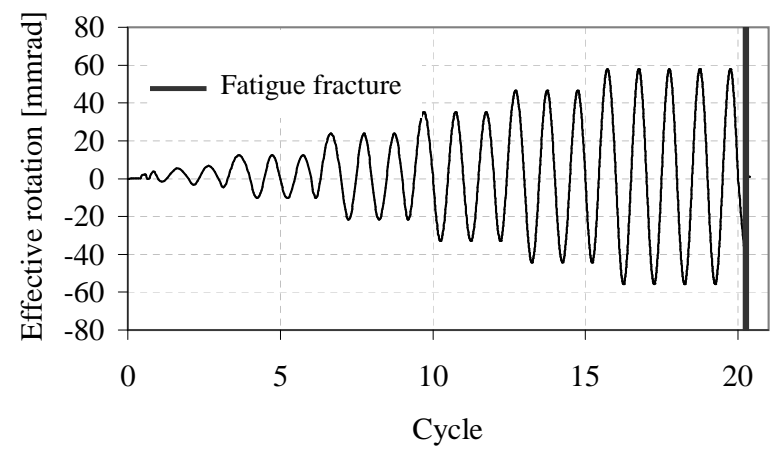

(a) Effective joint rotation

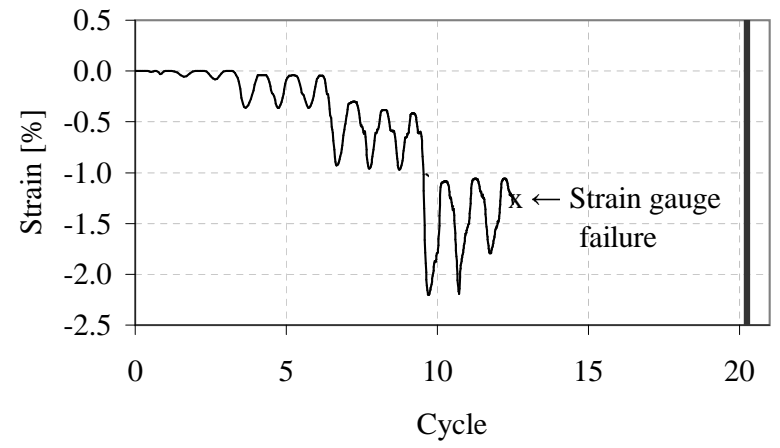

(b) Measured strains in the angle near the zone of observed fracture

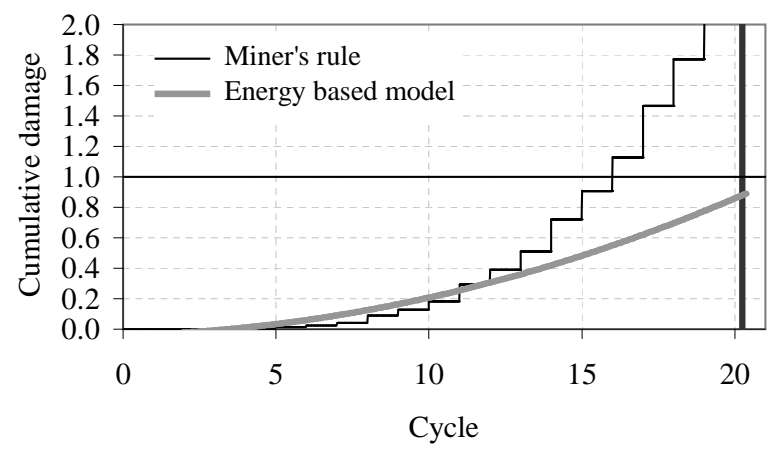

(c) Fatigue damage models [38]

Figure 13: Fatigue damage analysis for Specimen T10-A8-d40-Y 


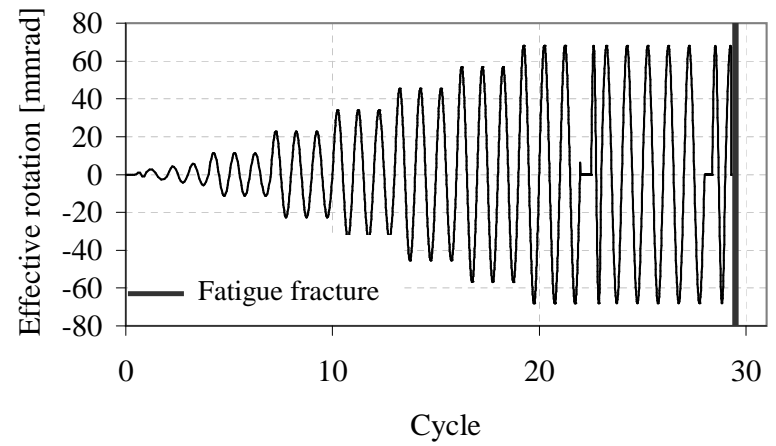

(a) Effective joint rotation

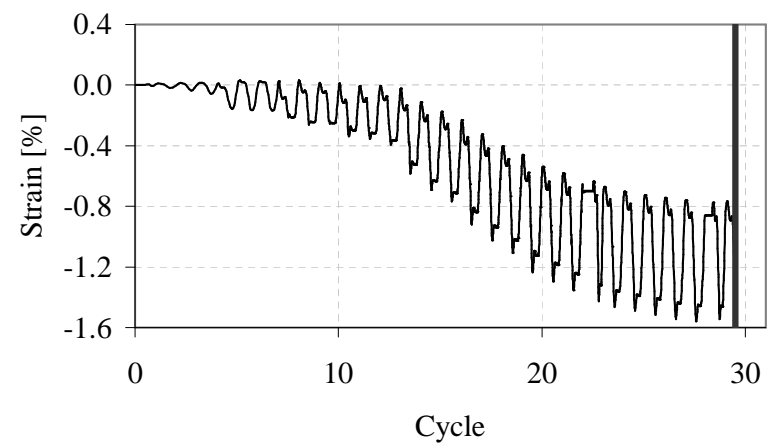

(b) Measured strains in the angle near the zone of observed fracture

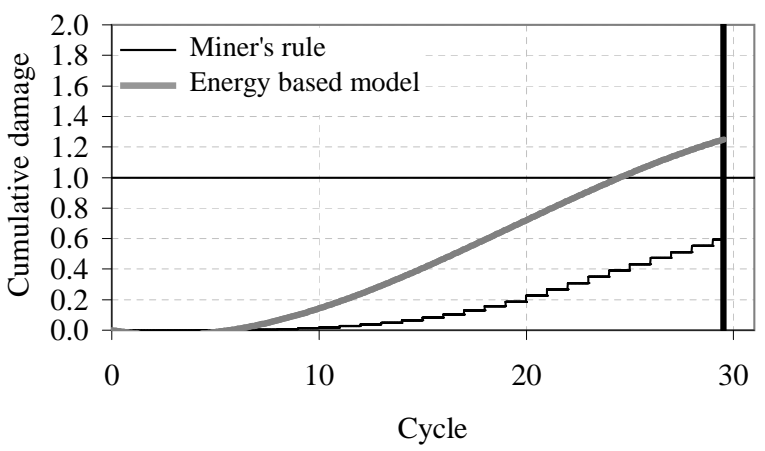

(c) Fatigue damage models [38]

Figure 14: Fatigue damage analysis for Specimen T6.3-A8-d40-Y 


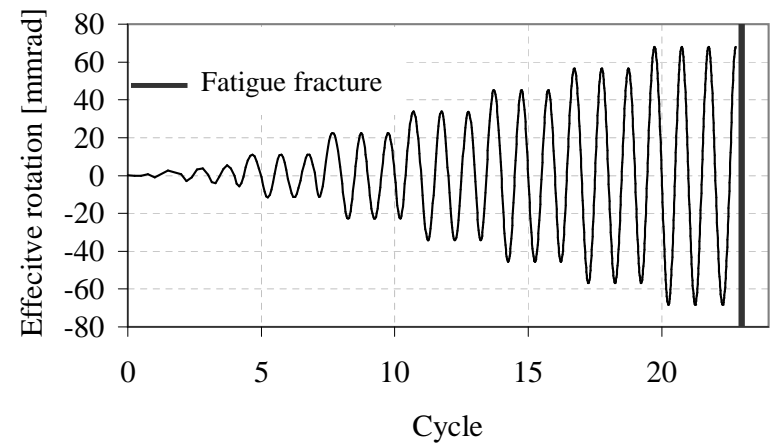

(a) Effective joint rotation

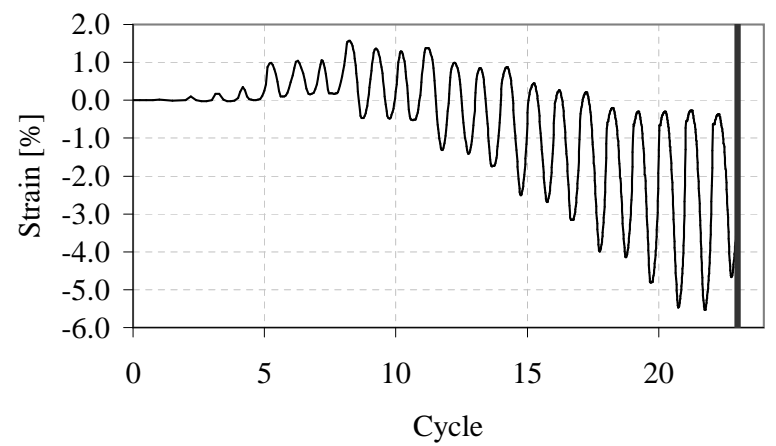

(b) Measured strains in the angle near the zone of observed fracture

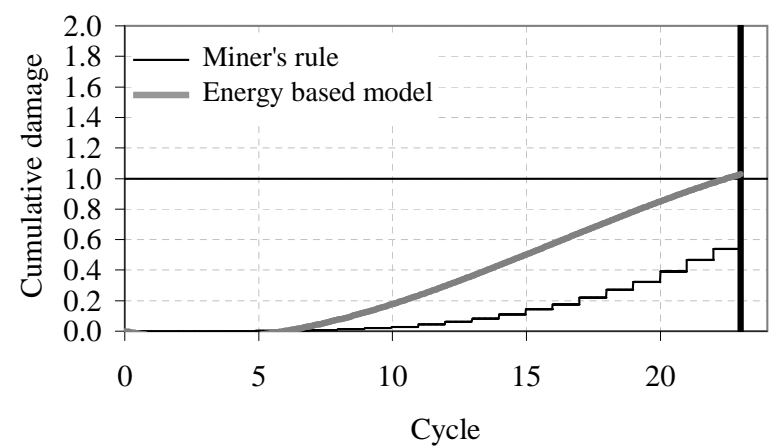

(c) Fatigue damage models [38]

Figure 15: Fatigue damage analysis for Specimen T10-A8-d65-Y 


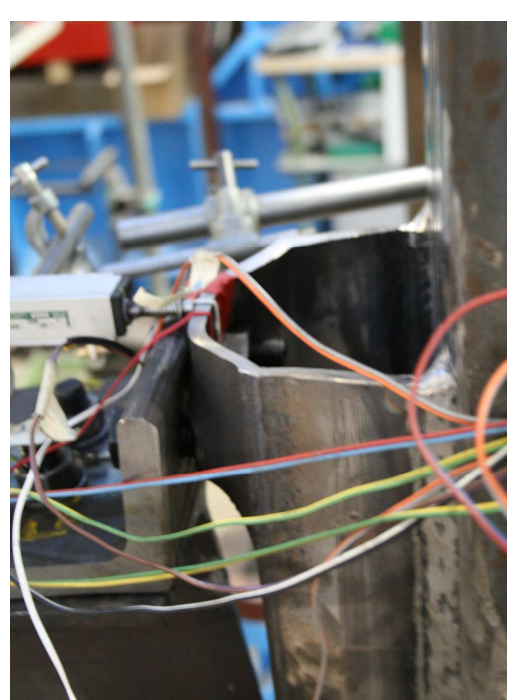

(a) Reverse channel plastic deformation observed in Specimen T6.3-A15-d40-M

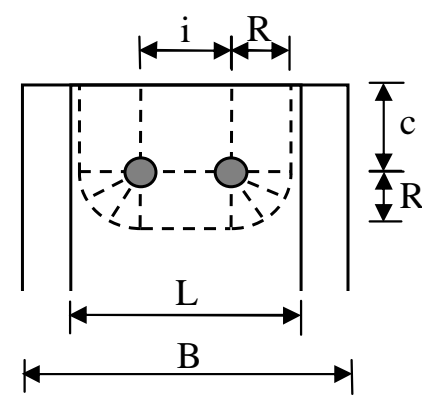

Front view

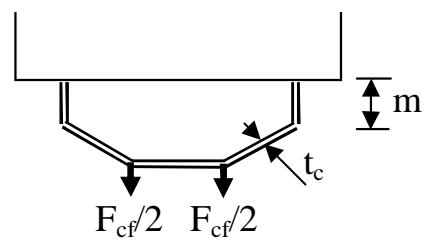

Plan view

(b) Idealized plastic mechanism for the reverse channel component

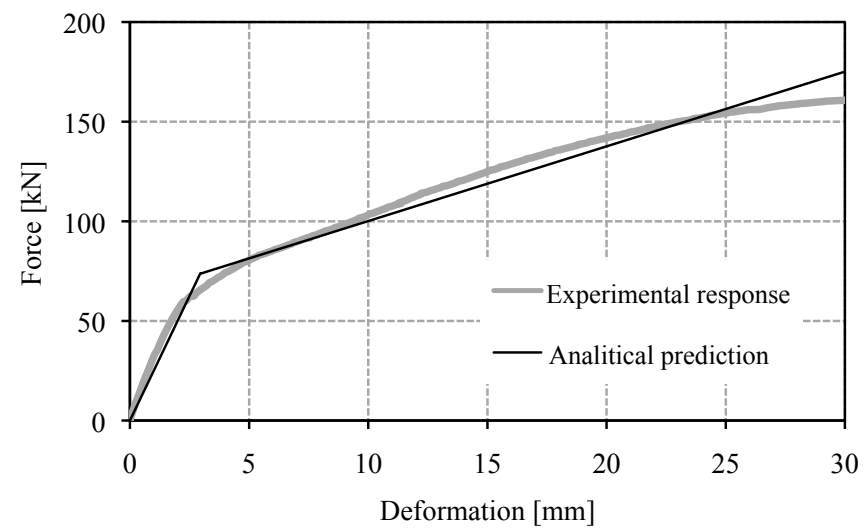

(c) Analytical prediction of channel behaviour in Specimen T6.3-A15-d40-M

Figure 16: Force-deformation characterization of reverse channel component

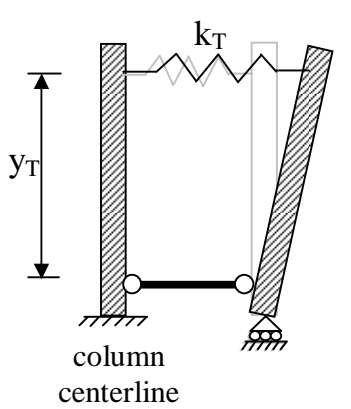

(a) Top and seat angle connections
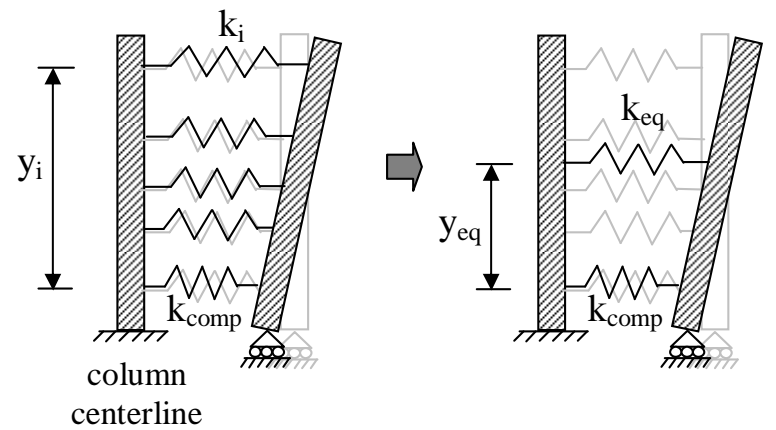

centerline

Figure 17: Mechanical model of angle connection 


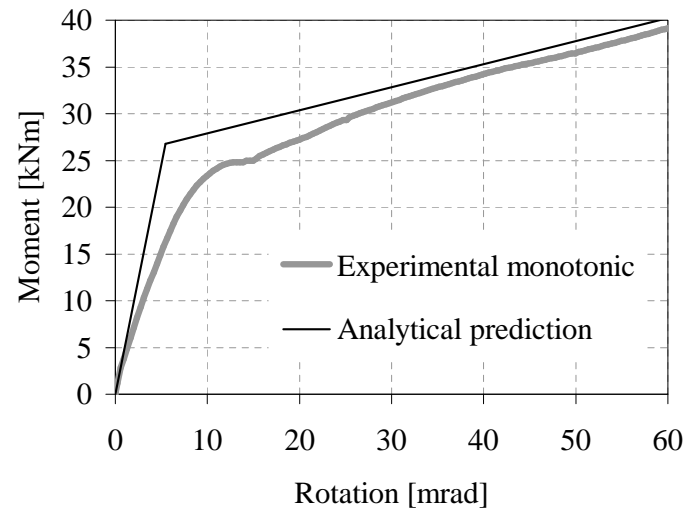

(a) Specimen T10-A8-d40-M

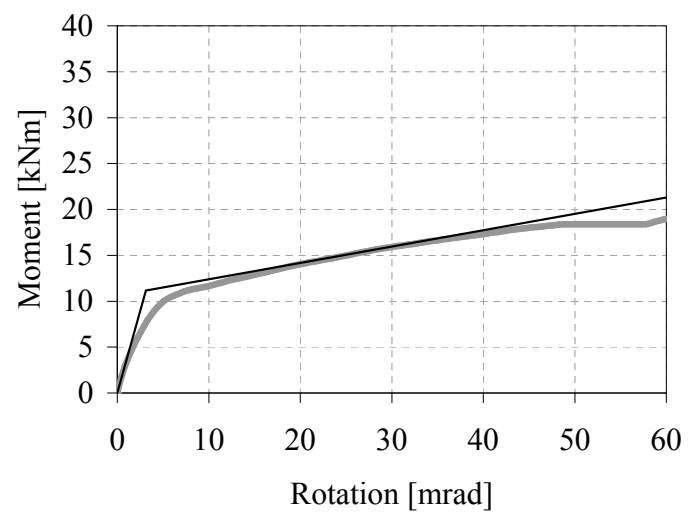

(c) Specimen T10-A8-d65-M

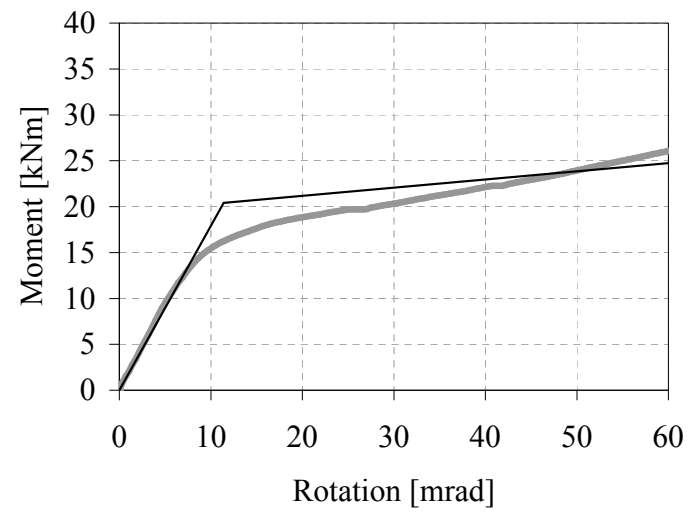

(b) Specimen T6.3-A8-d40-M

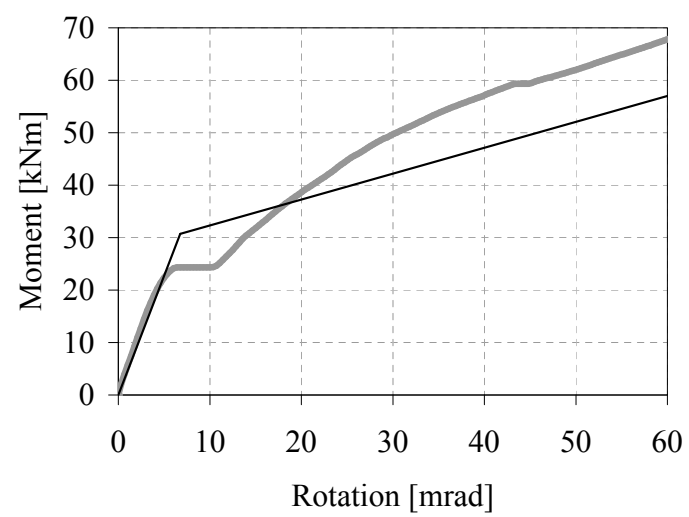

(d) Specimen W10-A8-d40-M

Figure 18: Comparison of experimental and predicted moment-rotation relationships for monotonic tests

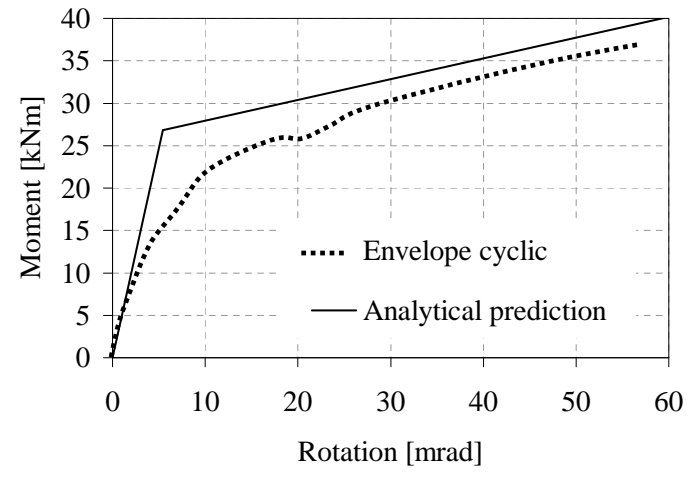

(a) Specimen T10-A8-d40-Y

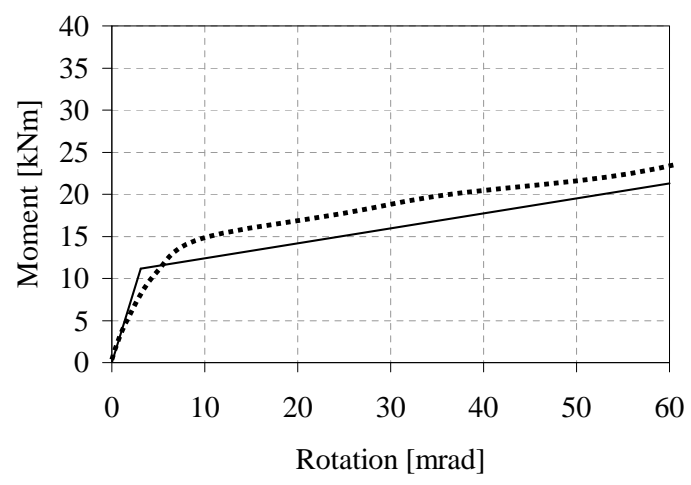

(c) Specimen T10-A8-d65-Y

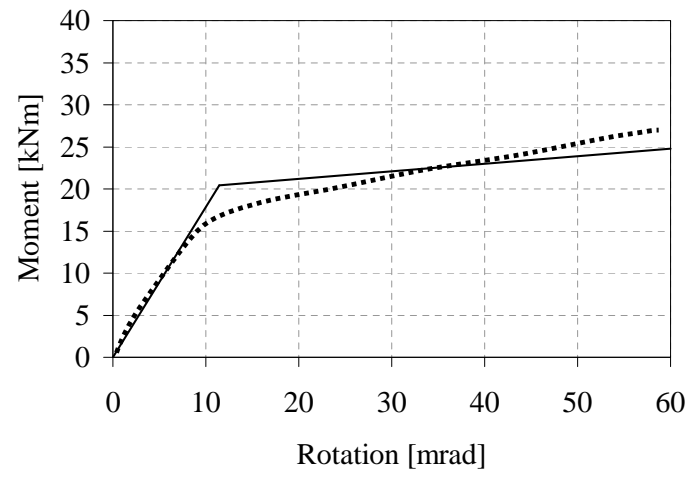

(b) Specimen T6.3-A8-d40-Y

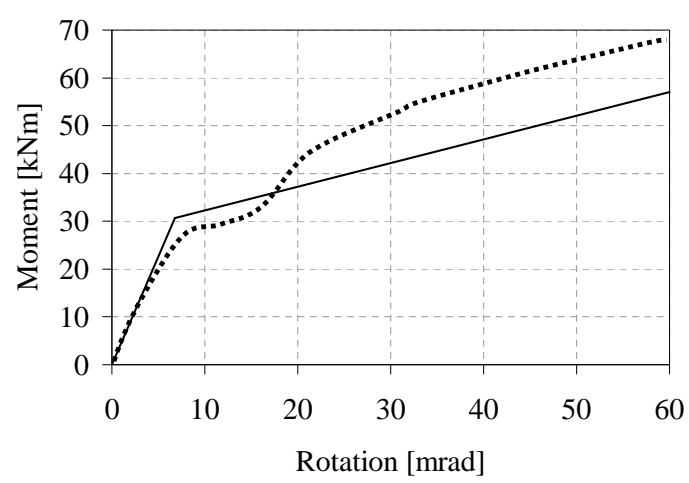

(d) Specimen W10-A8-d40-Y

Figure 19: Comparison of envelope of cyclic response and predicted moment-rotation relationships 